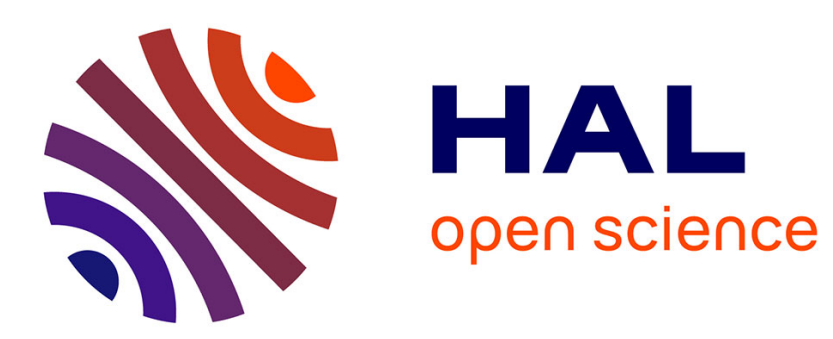

\title{
The effective elastic thickness (Te) of continental lithosphere: What does it really mean?
}

\author{
E.B. Burov, Michel Diament
}

\section{To cite this version:}

E.B. Burov, Michel Diament. The effective elastic thickness (Te) of continental lithosphere: What does it really mean?. Journal of Geophysical Research: Solid Earth, 1994, 100 (B3), pp.3905-3927. 10.1029/94JB02770 . insu-01354129

HAL Id: insu-01354129

https://hal-insu.archives-ouvertes.fr/insu-01354129

Submitted on 17 Aug 2016

HAL is a multi-disciplinary open access archive for the deposit and dissemination of scientific research documents, whether they are published or not. The documents may come from teaching and research institutions in France or abroad, or from public or private research centers.
L'archive ouverte pluridisciplinaire HAL, est destinée au dépôt et à la diffusion de documents scientifiques de niveau recherche, publiés ou non, émanant des établissements d'enseignement et de recherche français ou étrangers, des laboratoires publics ou privés. 


\title{
The effective elastic thickness $\left(T_{e}\right)$ of continental lithosphere: What does it really mean?
}

\author{
Evgene B. Burov' and Michel Diament \\ Laboratoire de Gravimétrie et Géodynamique J.E. 335, Institut de Physique du Globe de Paris, France
}

\begin{abstract}
It is well accepted that the lithosphere may exhibit nonzero mechanical strength over geological time and space scales, associated with the existence of non-lithostatic (deviatoric) stress. The parameter that characterizes the apparent strength of the lithosphere is the flexural rigidity $D$, which is commonly expressed through the effective elastic thickness $\left(T_{e}\right)$ of the lithosphere. Estimates of $T_{e}$ for oceanic lithosphere approximately follow the depth to a specific isotherm $\left(-600^{\circ} \mathrm{C}\right)$, which marks the base of the mechanical lithosphere. The physical meaning and significance of the effective elastic thickness for continents are still enigmatic, because for continental lithosphere estimates of $T_{e}$ bear little relation to specific geological or physical boundaries. Although high observed values of $T_{e}$ (70-90 km for cratons) can be partly explained by the present-day temperature gradients, the low values (10-20 km), in general, cannot. In addition, the elastic plate models are self-inconsistent in that they mostly predict intraplate stresses high enough to lead to inelastic (brittle or ductile) deformation, according to data of rock mechanics. To provide a basis for a physically consistent unified interpretation of the observed variations of $T_{e}$ for continental and oceanic lithosphere, we developed an analytical and numerical approach that allows direct treatment of $T_{e}$ in terms of the lithospheric rheology, thermal structure, and strain/stress distribution. Our technique is based on finding true inelastic and equivalent (effective) elastic solutions for the problem of deformation of the lithosphere with realistic brittleelasto-ductile rheology. We show that the thermal state (thermotectonic age) of the lithosphere is only one of at least three equally important properties that determine apparent values of $T_{e}$. These other properties are the state of the crust-mantle interface (decoupling of crust and mantle), the thickness and proportions of the mechanically competent crust and mantle, and the local curvature of the plate, which is directly related to the bending stresses. The thickness of the mechanically competent crust and the degree of coupling or decoupling is generally controlled by composition of the upper and lower crust, total thickness of the crust, and by the crustal geotherm. If decoupling takes place, it permits as much as $50 \%$ decrease of $T_{e}$, compared with $T_{e}$ implied from conventional thermal profiles. Comparison of the theoretically predicted $T_{e}$ with inferred values for different regions suggests that the lower crust of most continental plates has a low-temperature activation rheology (such as quartz) which permits crust and mantle decoupling. The curvature of the plate depends on the rheological structure and on the distribution of external loads applied to the plate (e.g., surface topography, sediment fill, and plate-boundary forces). Bending stresses created by major mountain belts are large enough to cause inelastic deformation (brittle failure and a ductile flow) in the underlying plate, which, in turn, leads to a 30 to $80 \%$ decrease of $T_{e}$ beneath such belts and less beneath the adjacent regions. The boundary forces and moments (e.g., due to the slab pull, etc.) lead to more localized but even stronger reductions in $T_{e}$ (e.g., plate necking in subduction zones). Our approach provides a feedback between the "observed" $T_{e}$ and rheology, allowing to constrain the lithospheric structure from estimates of $T_{e}$.
\end{abstract}

\section{Introduction}

The significance and utility of the flexural rigidity or the effective elastic thickness $\left(T_{e}\right)$ of the lithosphere are based on the concept that the gravitational equilibrium of the lithosphere can be maintained over geological time and space scales and that the resulting static deformation is explicable as flexure of a thin competent (elastic, plastic) plate overlying an inviscid fluid (asthenosphere). The deflection of the plate depends on the inferred properties of the plate (elastic, plastic, etc.). For example,

${ }^{1}$ On leave from Institute of Physics of the Earth, Moscow.

Copyright 1995 by the American Geophysical Union.

Paper number $94 \mathrm{JB} 02770$

$0148-0227 / 95 / 94 \mathrm{JB}-02770 \$ 05.00$ classical Airy model (local compensation) corresponds to a flexural model where the plate has no strength (zero rigidity, zero viscosity, etc.). Analytical and numerical models of the mechanical behavior of the lithosphere generally consider it as a closed system with "black box" response to external parameters: the input variables include surface and subsurface loads, density variations (i.e., mountain belts, magmatic underplating), forces (due to horizontal far-field stresses), and bending moments (related to plate curvature), whereas output variables consist of the geometry of the substratum (crystalline basement), deflections of the Moho, and gravity anomalies [e.g., Watts and Talwani, 1974; Dubois et al., 1974; McKenzie and Bowin, 1976; Forsyth, 1980; McNutt, 1980; Lyon-Caen and Molnar, 1983; De Rito et al., 1986; Sheffels and McNutt, 1986; Watts and Tome, 1992]. Irrespective of the real strain and stress distribution occurring within the deformed lithosphere, one can always estimate 
an "equivalent," or "effective," elastic (plastic, or visco-elastic) plate thickness that will relate the output to the input by matching observed deflection of the plate to the calculated deflection. However, the estimates of $T_{e}$ have little correlation with any geological or physical boundary within the continental lithosphere, although they provide a convenient basis for comparison between continental regions [e.g., McNutt et al., 1988; Ebinger et al., 1989; Bechtel et al., 1990]. This is partly because no information on the internal structure of the lithosphere is used, and the assumed mechanical properties of the plate parameterize only the "response function" of the lithosphere and therefore cannot provide any insights into the actual "black box" (continental lithosphere). We refer an estimate of $T_{e}$, obtained by the traditional methods, as the "observed" or "inferred" $T_{e}$. Such an estimate can be treated as a fixed parameter of the response function that roughly relates two general groups of observations: external loads (e.g., topography) and the plate deflections, caused by these loads (estimated from Moho or substratum geometry, gravity anomalies, bathymetry). Even if the physical meaning of the observed $T_{e}$ is not evident, it is clear that the deflection of a lithospheric plate, or gravity anomalies measured over it, yield an estimate of an average value of $T_{e}$.

In the past 10-15 years it became widely accepted [Caldwell and Turcotte, 1979; Watts et al., 1980; McNutt and Menard, 1982] that the major factor, responsible for variation of $T_{e}$ of oceanic plates, is the thermal structure of the oceanic lithosphere, which depends on its thermal age. The thermal age is usually defined as a period of time required for the lithosphere to reach its present-day thermal state, assuming that the lithosphere was initially melted. The thermal age of the oceanic lithosphere mostly coincides with the real (geological) age, except in zones of remarkable thermal anomalies. The lithosphere cools with time, becomes stronger, and $T_{e}$ increases. It was shown [Watts, 1978, Figure 1] that the value of $T_{e}$ approximately equals the depth to a specific geotherm of $450^{\circ} \mathrm{C}-600^{\circ} \mathrm{C}$ used to determine the base of the mechanical portion of the oceanic lithosphere. In spite of deviations from this relationship in the vicinity of some seamounts and oceanic islands [e.g., Calmant and Cazenave, 1986], or at the deep-sea trenches and large-offset fracture zones [McNutt and Menard, 1982; Wessel and Haxby, 1990], it generally works well in the oceans (Figure 1). Any significant deviations of the observed $T_{e}$ from that predicted from the conventional thermal model are usually treated as indicators of thermal anomalies (though $M c A d o o$ et al. [1985] have shown that intense bending, for example, at trenches, may result in decrease of the strength of the lithosphere).

Some of the scatter in values of $T_{e}$ obtained by different authors can result from use of different material parameters for its estimation [Deplus, 1987]. $T_{e}$ is equal to $\left(12 D\left(1-v^{2}\right) / E\right)^{-3}$ where $D$ is the flexural rigidity. Typical variations in assumed values of $E$ and $v$ (Young's modulus and Poissons's ratio, respectively) may lead to $\sim 10-20 \%$ scatter in estimates of $T_{e}$ (Thus the flexural rigidity $D$ is less uncertain than $T_{e}$, and for comparison between different regions or data sources it is important to know both parameters, $D$ and $T_{e}$.) The quality of the bathymetry and other data, as well as the different techniques used for estimation of $T_{e}$ (admittance, coherence, forward modeling), also cause discrepancies between the theoretical predictions and estimates of $T_{e}$ inferred from observations of lithospheric flexure [e.g., Wessel, 1993; Filmer et al., 1993]. Another possible source of uncertainty is the usual neglect by possible horizontal stresses in computing the flexure. Indeed, the horizontal stresses can be neglected within the assumption that the lithosphere is perfectly elastic and flexes in a stable regime [Turcotte and Schubert, 1982]. However, in the case of inelastic lithosphere the effect of horizontal stresses is much more important due to possible strain softening and development of instabilities [Cloetingh et al, 1982; Cloetingh, S., and E.B. Burov, Thermomechanical struc-

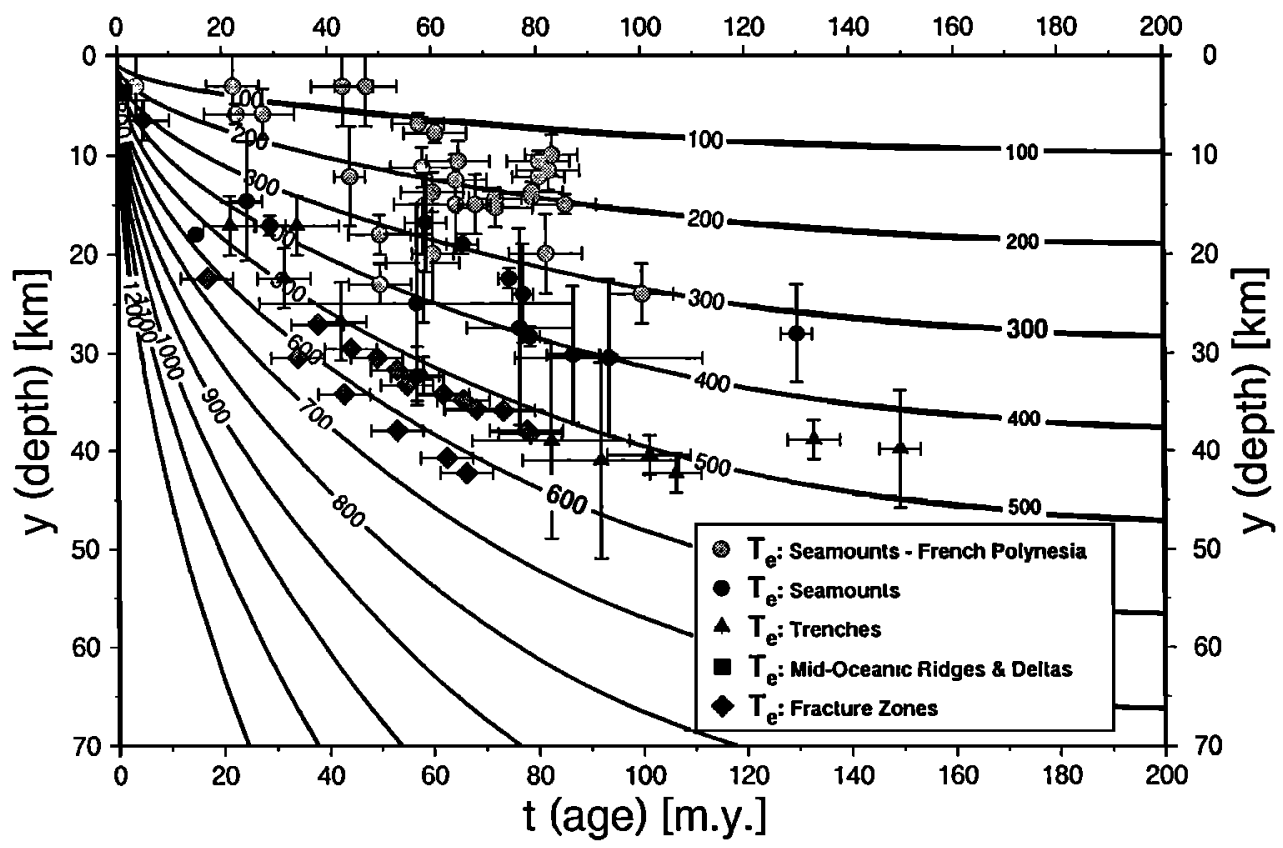

Figure 1. Compilation of observed elastic thickness $\left(T_{e}\right)$ against age of the oceanic lithosphere at the time of loading. The isotherms are calculated from a plate cooling model with an equilibrium thermal thickness of $125 \mathrm{~km}$ (appendix) [Parsons and Sclater, 1977]. Data sources: as given by Deplus [1987], Smith et al. [1989], and Watts, [1992]. Additional points are taken from Calmant and Cazenave [1986], Wessel and Haxby [1990], Judge and McNutt [1991], Wessel [1993], and Filmer at al. [1993]. 
ture of the European continental lithosphere: Constraints from rheological profiles and EET estimates, submitted to: Geophys. $J$. Int., 1994]. Finally, the notion of $T_{e}$ is linked to the assumptions of small plate deflections, thin plate approximation, and cylindrical bending [Turcotte and Schubert, 1982]. These assumptions are not always completely satisfied in studies on modeling of the lithospheric flexure, which may result in inaccurate solutions for the plate deflection and, consequently, in overestimates or underestimates of $T_{e}$. To summarize, we would assume that $25 \%$ uncertainty is a quite realistic estimate for the accuracy of most data on $T_{e}$.

In contrast to oceanic regions, the concept of age/temperature dependence of $T_{e}$ is only crudely applicable to continental lithosphere (Figure 2) [e.g., Karner et al., 1983]. Although it is clear that the strength of the continental lithosphere is somehow controlled by its thermal state [e.g., Sahagian and Holland, 1993], many authors have shown that $T_{e}$ in the continents cannot be described by a relationship with a single parameter like age/temperature [e.g., Cochran, 1980; McNutt et al., 1988;
McNutt, 1990; Banda and Cloetingh, 1992; Watts, 1992; Kruse and Royden, 1994]. It appears that $T_{e}$ also depends on distribution of loads, dip angle, and curvature of the plate. $T_{e}$ in the continents has a wide range of values (5-110 km, Figure 2) having a "bimodal" distribution with a primary peak at $10-30 \mathrm{~km}$ and a secondary one at $70-90 \mathrm{~km}$ [Watts, 1992]. In addition, the values of $T_{e}$ may exhibit large spatial variations within the same plate [Lyon-Caen et al., 1985; Watts, 1988; Ebinger et al., 1989; Bechtel et al., 1990; Y.H. Poudjom-Djomani, J.M. Nnange, M. Diament, C.J. Ebinger and J.D. Fairhead, Effective elastic thickness and crustal thickness variations in the West-Central Africa inferred from gravity data, submitted to Joumal Geophysical Research, 1994]. All this naturally has led to doubts about the significance of continental $T_{e}$ estimates, regardless of the specifical technique used for its determination: spectral methods (admittance, coherence) or more reliable forward modeling.

The notion of effective elastic thickness also meets problems in comparisons with the data from rock mechanical observations which indicate that on geological time and deformation scales the

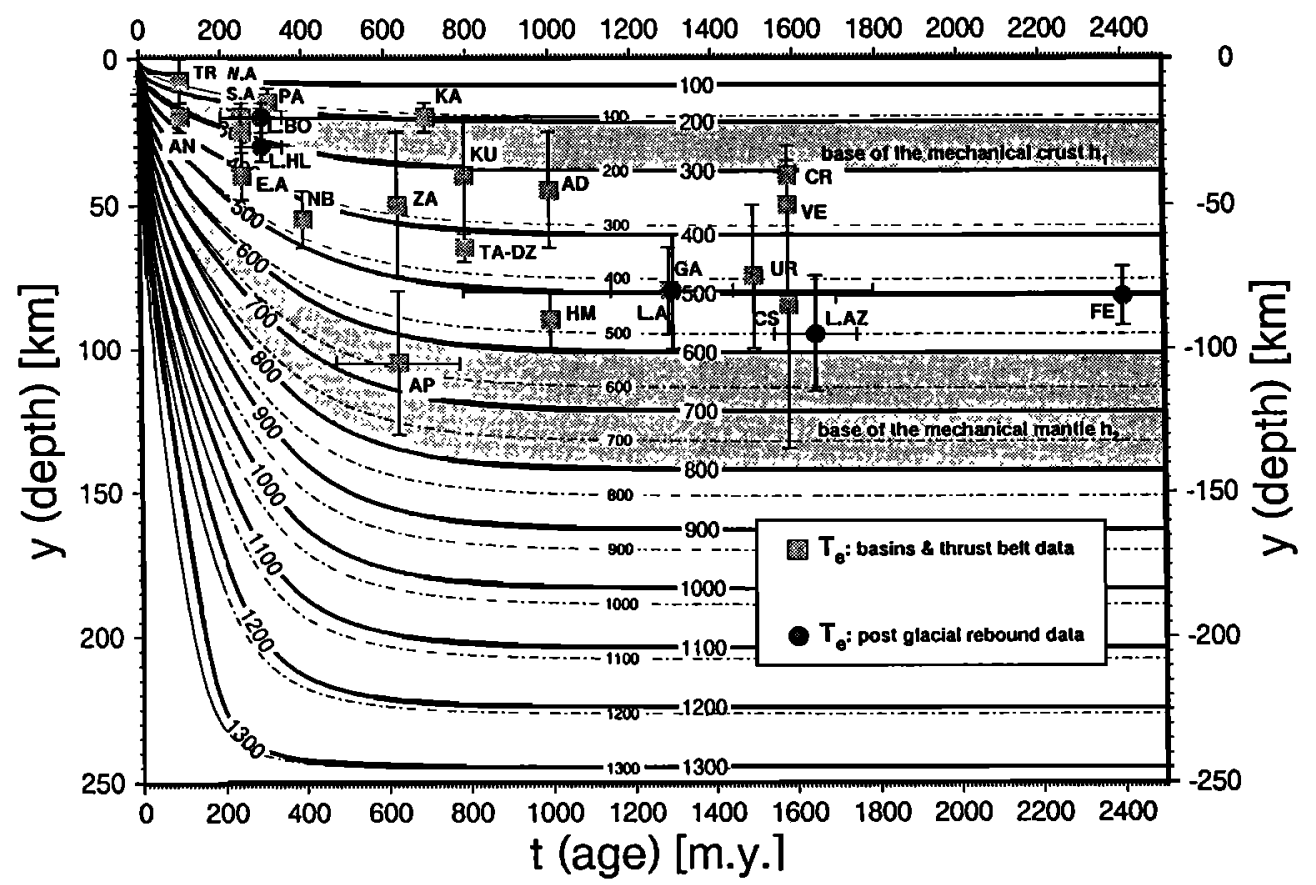

Figure 2. Compilation of observed elastic thickness $\left(T_{e}\right)$ against age of the continental lithosphere at the time of loading and the thermal model of the continental lithosphere (equilibrium thermal thickness of $250 \mathrm{~km}$ (appendix). The dashed lines are isotherms for a pure cooling model; the solid lines are those for additional radiogenic heat generation in the crust. Solid squares are estimates of $T_{e}$ in collision zones (foreland basins, thrust belts); solid circles correspond to postglacial rebound data. Isotherms $250^{\circ} \mathrm{C}-300^{\circ} \mathrm{C}$ mark the base of the mechanically strong upper crust (quartz). The isotherms $700^{\circ} \mathrm{C}-750^{\circ} \mathrm{C}$ mark the base of the competent mantle (olivine). Note that there is no significant changes in the thermal structure of the lithosphere after $\sim 750 \mathrm{Ma}$, though there are significant reductions in $T_{e}$ even for these ages. The notations for foreland basins/mountain thrust belts data are E.A, Eastern Alps; W.A., Western Alps; AD, Andes (Sub Andean); AN, Apennines; AP, Appalachians; CR, Carpathians; CS, Caucuses; DZ, Dzungarian Basin; HM, Himalaya; GA, Ganges; KA, Kazakh shield (North Tien Shan); KU, Kunlun (South Tarim); NB, North Baikal (the North Baikal is believed to represent a "broken" rift currently dominated by flexural deformations [Burov et al., 1994]); TA, Central and North Tarim; PA, Pamir; TR, Transverse Ranges; UR, Urals; VE, Verkhoyansk; ZA, Zagros. Abbrevitions for postglacial rebound data are L.A., Lake Algonquin; FE, Fennoscandia; L.AZ, Lake Agassiz; L.BO, Lake Bonneville; L.HL, Lake Hamilton. Data sources are CS, UR (from the side of the Russian plate), Stakhovskaya and Kogan [1993]; S.A., AN., CR., HM., Royden [1993] and Kruse and Royden [1994]; NB, Burov et al. [1994]; KA, TA, PA, Burov et al. [1990] and Burov and Diament [1992]; KU, GA, AD, TA, Lyon-Caen and Molnar [1983], Lyon-Caen and Molnar [1984], and Lyon-Caen et al. [1985]; W.A, E.A., AP, GA, Kamer and Watts, [1983]; TR, Sheffels and McNutt, [1986]; VE, McNutt et al. [1988]. DZ, Benedetti [1993]; FE, Mömer [1990]. Other data sources (ZA, L.A., L.AZ, L.BO, L.HL) are as given by Watts [1992]. 
lithospheric rocks cannot behave completely elastically. Goetze and Evans [1979] have shown that one needs to consider empirical rock mechanics data describing the temperature, pressure, and deviatoric stress-strain rate relations of lithospheric rocks (brittle and ductile failure) to explain observed deviatoric stress distributions. The data on stresses and strains in collisional belts require that the modeling approach takes into account experimental studies on brittle and ductile behavior of lithospheric rocks, because the elastic plate models predict stresses sufficiently high to lead to inelastic behavior, and provide poor representations of the distribution of the seismicity with depth [Goetze and Evans, 1979; Lyon-Caen and Molnar, 1983; Burov and Diament, 1992]. It is evident that there is a dependence between $T_{e}$ and at least (1) composition and geometry of the plate, (2) external forces, and (3) thermal structure [e.g., McNutt and Menard, 1982]. McAdoo et al. [1985] considered these ideas and developed a three-layer (brittle-elastic-ductile) numerical model for the flexure of the oceanic lithosphere and examined the relationship between plate strength, age, and bending moments. Ranalli [1994] also made analytical estimates for dependence between plate strength and plate curvature for continental lithosphere with coupled ("oceanic type") work-hardening rheology. The continental lithosphere shows a more complex rheological stratification than the ocean floors, partly because of its thicker crust, its longer history, and its modification by surficial processes (e.g., erosion, sedimentation and orogenesis). To represent flexure of the continental lithosphere, Burov and Diament [1992] have developed a numerical model of bending of a plate with multilayered nonlinear brittle-elasto-ductile rheology that predicts geometry of areas of ductile and brittle failure and the distribution of extensional and compressional stresses. They also showed that the dimensions of inelastic zones in the flexed continental lithosphere may exceed the dimensions of the areas that remain quasi-elastic.

Despite the fact that there are serious problems with the interpretation of the effective elastic thickness in continents, $T_{e}$ is a useful easy-to-estimate parameter that provides important information on the mechanical and thermal state of the lithosphere. However, its understanding requires thorough revision and quantitative interpretation in terms of lithospheric rheology and structure. The general purpose of this paper is an attempt to give such interpretation of behavior and distributions of $T_{e}$ in continents and to provide an easily reproducible numerical approach relating continental and oceanic $T_{e}$ to lithospheric rheology, regional tectonic setting, and thermal structure. This provides a feedback between the "observed" $T_{e}$ and rheology, allowing us to put constraints on the lithospheric structure from estimates of $T_{e}$.

\section{Mechanical Properties of the Lithosphere and Major Deviations From Elasticity}

The major contradiction between the assumption of a linear elastic rheology and what we know about properties of the rocks is that the elasticity assumes no dependence between strain rates, stresses, and time. This assumption implies that rock properties are independent of stress and strain (that is linear increase of stress with increase of strain, which results in large or overestimated tectonic stresses typically predicted by elastic models [e.g., Goetze and Evans, 1979; Lyon-Caen and Molnar, 1983]).

\section{Mechanical Properties of the Rocks: Experimental Data}

The finite strain properties of the lithosphere and underlying asthenosphere can be described by empirical constitutive relations that express the yield stress limits of the dominant lithologies within the continental and oceanic lithosphere, as functions of strain rate, temperature, pressure, and activation energy [Goetze, 1978; Brace and Kohlstedt, 1980; Kirby, 1983; Kirby and Kronenberg, 1987; Ranalli and Murphy, 1987]. The dominant lithologies for the continental lithosphere are basically quartz (upper crust), diabase, quartz-diorite, plagioclase (lower crust), and olivine (mantle). Although most of experimental constitutive relations are established for minerals (like quartz and olivine), it is believed that the behaviour of rocks is controlled by the properties of the weakest among the dominant minerals [e.g., Brace and Kohlstedt, 1980]. Combining rheological layers (yield-stress envelope, $Y S E$ ), one can examine the competence of depth horizons within the lithosphere for a given deviatoric stress. The rocks may deform quasi-elastically if the deviatoric stresses are below the yielding limits, otherwise they fail either by brittle sliding or by ductile creep flow. Thus the upper areas of the crust and mantle are controlled by predominantly brittle (effectively plastic) failure, commonly associated with seismic activity [Mareschal and Gangi, 1977; Mareschal and Kuang, 1986; Talwani and Rajendran, 1991; Long and Zelt, 1991]. The deeper, hotter lithosphere is controlled by temperature-activated creep. The intermediate levels, where the yielding limits are not exceeded, can be considered as elastic. The major difference between the crustal and upper mantle rocks is that the ductile flow of the crustal rocks (e.g., quartzites, granites) occurs at much lower temperatures than those of olivine. This suggests that the crust may flow under much lower stresses than the mantle.

In a generalized form the relationship between strain rate and stress in a point with Cartesian coordinate $x, y, z$ in time $t$ is given by

$$
\dot{\varepsilon}(x, y, z, t)=A(x, y, z, t) \sigma(x, y, z, t)^{n}
$$

or

$$
\dot{\varepsilon}_{i j}(x, y, z, t)=A(x, y, z, t) \sigma(x, y, z, t)^{n-1} \sigma_{i j}(x, y, z, t)
$$

where $\dot{\varepsilon}=\left(1 / 2 \dot{\varepsilon}_{i j} \dot{\varepsilon}_{y j}\right)^{1 / 2}$ and $\sigma=\left(1 / 2 \sigma_{y j} \sigma_{i j}\right)^{\frac{1}{2}}$ are the effective strain rate and effective stress (second invariants). The variables $n$ (stress exponent) and $A$ (constitutive parameter) describe properties of a specific material.

The ductile behaviour of most lithospheric minerals can be described by (la) with $A=A^{*} a^{-m} \exp \left(-H^{*} / R T\right)$ and $n=3-5$, where $A^{*}$ is a material constant, $a$ is the mineral grain size, $m$ is established experimentally. $H^{*}$ is the activation entalphy, $R=1.986 \mathrm{cal}^{(\mathrm{mol} \mathrm{K})^{-1}}$ is the gas constant, and $T$ is the temperature (in Kelvin) [Kirby and Kronenberg, 1987; Ranalli and Murphy, 1987; Mackwell et al., 1990]. For two-dimensional case (e.g., plate approximation), the following Arrhenius relation holds for ductile creep:

$$
\dot{\varepsilon}=\left(A^{*} a^{-m}\right) \exp \left(-H^{*} / R T\right)\left(\sigma_{1}-\sigma_{3}\right)^{n}
$$

or

$$
\left(\sigma_{1}-\sigma_{3}\right)=\left(\dot{\varepsilon}\left(A^{*}\right)^{-1} a^{m}\right)^{1 / n} \exp \left(H^{*} / n R T\right)
$$

where $\left(\sigma_{1}-\sigma_{3}\right)=\sigma^{d}$ is the deviatoric yielding stress, defined as the difference between the maximum and minimum principal stresses $\sigma_{1}, \sigma_{3}$. Equation (1b) is valid for both major creep mechanisms, diffusion of atoms through the crystal grains, and migration of dislocations of the crystalline structure. The first mechanism depends on the grain size, the second one depends on the crystalline structure of the material. The diffusion creep ( $m \neq$ 0 ) is important only for very low stresses, strain rates and small grain sizes, otherwise the dislocation creep $\left(m=0 ; a^{-m}=1\right)$ dominates [Turcotte and Schubert, 1982; Ruttler and Brodie, 1988; 
Hopper and Buck, 1993]. The estimated lithospheric conditions mostly fall in the dislocation creep field [e.g., Kusznir and Park, 1987; Kusznir, 1991], and therefore we do not consider the diffusion creep in this study.

The ratio of the stress to strain rate gives a basic effective non-Newtonian viscosity: $\mu_{e f f}=\sigma^{d} / 2 \dot{\varepsilon}$. For rheologically significant strain rates of $10^{-17}-10^{-14} \mathrm{~s}^{-1}$ a critical temperature of around $250^{\circ}-300^{\circ} \mathrm{C}$ must be exceeded for ductile flow of quartz, whereas for olivine it should be $600^{\circ}-700^{\circ} \mathrm{C}$ [Brace and Kohlstedt, 1980; Tsenn and Carter, 1987; Kusznir and Park, 1987]. The strong temperature control on the ductile rheology thus requires a knowledge of the thermal structure of the plate. In the appendix we obtain an estimate of the depth(y)-time $(t)$ temperature $(T)$ distribution for the half-space cooling model, constrained by heat flow and xenolith data, and accounting for radiogenic heat generation in the crust and viscous frictional heating at the crust-mantle boundary.

In steady state deformation the strain rate should be in balance with the imposed flow stress. If the imposed stress is lower than the steady state ductile strength, almost no ductile deformation will occur and the effective viscosity and the stress relaxation time will be very high. In this case the material can be considered as elastic. Similar conditions apply when the imposed stress does not reach the brittle (plastic) strength.

In this paper we adopt the following material constants for the creep law (dry minerals).

Quartzite: $A^{*}=5 \times 10^{-12} \mathrm{~Pa}^{-n} \mathrm{~s}^{-1}, H^{*}=190 \mathrm{~kJ} \mathrm{~mol}^{-1}, n=3$ [Brace and Kohlstedt, 1980]; quartz-diorite: $A^{*}=5.01 \times 10^{-15} \mathrm{~Pa}^{-n} \mathrm{~s}^{-1}$, $H^{*}=212 \mathrm{~kJ} \mathrm{~mol}^{-1}, n=2.4$ [Carter and Tsenn, 1987]; diabase: $A^{*}=6.31 \times 10^{-20} \mathrm{~Pa}^{-n} \mathrm{~s}^{-1}, H^{*}=276 \mathrm{~kJ} \mathrm{~mol}^{-1}, n=3.05$ [Carter and Tsenn, 1987]; olivine/dunite (dislocation climb, $\sigma_{1}-\sigma_{3} \leq 200$ $\mathrm{MPa}$ ): $A^{*}=7 \times 10^{-14} \mathrm{~Pa}^{-n} \mathrm{~s}^{-1} ; H^{*}=520 \mathrm{~kJ} \mathrm{~mol}^{-1} ; n=3$ [e.g., Kirby and Kronenberg, 1987]; olivine (Dorn's dislocation glide, $\sigma_{1}-\sigma_{3} \geq 200 \mathrm{MPa}$ ):

$\dot{\varepsilon}=\dot{\varepsilon}_{0} \exp \left[-H^{*}\left(1-\left(\sigma_{1}-\sigma_{3}\right) / \sigma_{0}\right)^{2} / R T\right]$ where $\dot{\varepsilon}_{0}=5.7 \times 10^{11} \mathrm{~s}^{-1}$,

$\sigma_{0}=8.5 \times 10^{3} \mathrm{MPa} ; H^{*}=535 \mathrm{~kJ} \mathrm{~mol}^{-1}$ [Carter and Tsenn, 1987]

For the basic strain rate we adopt the value of $3 \times 10^{-15} \mathrm{~s}^{-1}$ that is found to be most representative in the continental areas [e.g., Molnar and Tapponnier, 1981; Molnar and Deng Qidong, 1984].

In the real Earth the stress-strain dependence always has characteristic timescales. Thus both plastic and elastic rheologies are rather physical assumptions, because neither plastic nor elastic rheology assumes time dependence between stress and strain. Nevertheless, brittle behavior of materials can be modeled as quasi-plastic by assuming that $n \rightarrow \infty$ whilst the strain rate $\dot{\varepsilon}$ remains finite. To describe transition to the plastic regime of deformation, one can use, for example, the Von Mises criterion of plastic yielding:

$$
2 \sigma_{0}^{2}=\left(\sigma_{1}-\sigma_{2}\right)^{2}+\left(\sigma_{1}-\sigma_{3}\right)^{2}+\left(\sigma_{2}-\sigma_{3}\right)^{2}
$$

where $\sigma_{1}, \sigma_{2}, \sigma_{3}$ are principal stresses and $\sigma_{0}$ is yielding stress. Conditions of brittle failure in a 2-D case are similar to (2a) [Byerlee, 1978]:

$$
\begin{gathered}
\sigma_{3}=\left(\sigma_{1}-\sigma_{3}\right) / 3.9 \text { if } \sigma_{3}<120 \mathrm{MPa} \\
\sigma_{3}=\left(\sigma_{1}-\sigma_{3}\right) / 2.1-100 \text { if } \sigma_{3} \geq 120 \mathrm{MPa}
\end{gathered}
$$

where $\left(\sigma_{1}-\sigma_{3}\right)=\sigma^{b}$ is the differential yielding stress. The brittle strength is to a first approximation insensitive to temperature and is mainly pressure-controlled. Byerlee [1978] also found that initiation of slip on precut rock faces is not sensitive to rock type.

The elastic, or quasi-elastic behavior can be modeled by assuming infinite strain rate at finite value of stress:

$$
\begin{gathered}
\varepsilon_{i k}=E^{-1}\left((1+v) \sigma_{i k}-v \sigma_{l l} \delta_{i k}\right) \\
\sigma_{i k}=E(1+v)^{-1}\left(\varepsilon_{i k}+v(1-2 v)^{-1} \varepsilon_{l l} \delta_{i k}\right)
\end{gathered}
$$

Typical values for $E$ (Young's modulus) and $v$ (Poissons's ratio) are $6.5 \sim 8 \times 10^{10} \mathrm{~N} / \mathrm{m}^{2}$ and 0.25 respectively [e.g., Watts, 1978; Turcotte and Schubert, 1982]. In terms of principal stresses $\sigma_{1}, \sigma_{2}, \sigma_{3},(3 \mathrm{~b})$ can be written as:

$$
\begin{gathered}
\sigma_{j}=E(1+v)^{-1} \sigma_{j}+E v((1+v)(1-2 v))^{-1}\left(\varepsilon_{1}+\varepsilon_{2}+\varepsilon_{3}\right)= \\
2 \mu \sigma_{j}+\lambda\left(\varepsilon_{1}+\varepsilon_{2}+\varepsilon_{3}\right)
\end{gathered}
$$

where $j=1,2,3$ and $\lambda$ and $\mu$ are Lamé's constants.

\section{The Yield-Stress Envelope (YSE) and Uncertainties on Its Parameters}

Combining rheological laws (1), (2b), and (3b) one can form piecewise continuous yield-stress envelope (YSE) [Goetze and Evans, 1979, Figure 3]. The ISE can be defined as a contour $\sigma^{f}=\sigma^{f}(x, y, t, \dot{\varepsilon})$ such that

$$
\sigma^{f}=\operatorname{sign}(\varepsilon) \min \left(\left|\sigma^{b}(x, y, t, \dot{\varepsilon}, \operatorname{sign}(\varepsilon))\right|,\left|\sigma^{d}(x, y, t, \dot{\varepsilon})\right|\right)
$$

where $\sigma^{b}(x, y, t, \dot{\varepsilon}, \operatorname{sign}(\varepsilon)), \sigma^{d}(x, y, t, \dot{\varepsilon})$ are the "brittle" and "ductile" yielding limits from (1) and (2b), $y$ is downward positive. Due to asymmetry of the Byerlee's law (2b), the absolute value of the yield stress depends on the mode of deformation: for extension $\operatorname{sign}(\varepsilon)=1$; for compression $\operatorname{sign}(\varepsilon)=-1$. The differential stress $\sigma(\varepsilon)$ for the strain $\varepsilon=\varepsilon(x, y, t, \dot{\varepsilon})$ can be defined as:

$$
\sigma(\varepsilon)=\operatorname{sign}(\varepsilon) \min \left(\left|\sigma^{f}\right|,\left|\sigma^{e}(\varepsilon)\right|\right)
$$

where $\sigma^{e}(\varepsilon)$ is the elastic differential stress, defined accordingly to (3b). Equation (5) means that the lithosphere material behaves elastically if the imposed stress does not exceed the yield strength. The elastic "core" of the lithosphere can be interpreted as the depth interval where neither ductile creep nor brittle failure alter the stress.

The YSE allows one to locate competent zones within the lithosphere and zones of ductile or brittle failure for a given local gradient of deviatoric stresses. It also allows a definition of the integrated lithospheric strength $(B)$ as simply the integral of $\sigma^{f}$ over depth [e.g., Hopper and Buck, 1993]:

$$
B=\int_{0}^{\infty} \sigma^{f}(x, y, t, \dot{\varepsilon}) d y
$$

For an elastic plate the notion of the integrated strength is quite close to that of the flexural rigidity $(D)$, defined in the next section.

Naturally, the experimental rheological laws used to define the YSE bear some uncertainties in their parameters. We now discuss the effect of these uncertainties.

Variations in the mineral composition: Wet/dry rheology, porous fluids. As one can see from Figure $3 a$, the assumed difference in the mechanical properties of the upper crust, lower crust, and the mantle may lead to an appearance of weak zone(s) in the lower crust that permits mechanical decoupling of the upper crust from the mantle by ductile flow in the weak zone [e.g., Chen and Molnar, 1983; Zoback et al., 1985; Lobkovsky, 1988; Bird, 1991; Lobkovsky and Kerchman, 1992]. Decoupling can be expected if the ductile strength of the lower crust is controlled by a mineral composition with temperature of creep activation lower than the temperature at the crust-mantle transition (Moho boundary). For most commonly assumed quartz-dominated crust, decoupling should be permanent, except when the crust is very thin $(<20-25 \mathrm{~km})$. For other crustal compositions it probably 

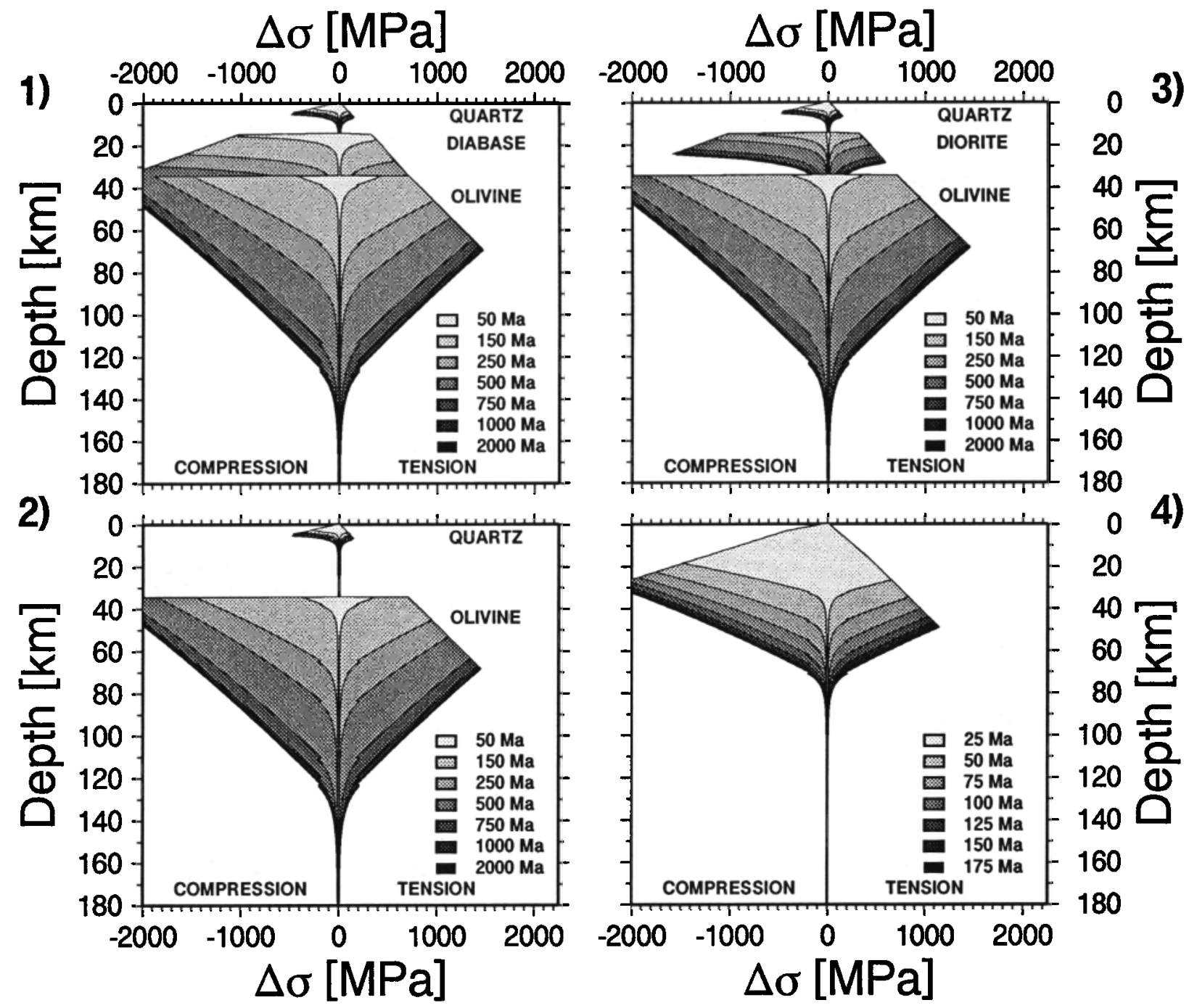

Figure 3a

Figure 3. Yield-strength envelopes (YSEs) for different thermal ages, strain rates and crustal compositions. Crustal thickness $h_{c}=35 \mathrm{~km}$. (a) Dependence of the yield strength on age. Numbers 1, 2, and 3 correspond to continental lithosphere with different compositions of the lower crust : 1 , high-temperature of creep activation (diabase); 2, low temperature of creep activation (quartzites, granites); 3, intermediate temperature of creep activation (quartz-diorite). Number 4 corresponds to the oceanic lithosphere. The upper parts of the YSEs are formed by the brittle yielding limits, the lower ones by the ductile creep yielding limits. Note that the crust is practically always detached from the mantle for a young continental lithosphere (age $<250 \mathrm{Ma}$ ). For the old lithosphere (age $>750 \mathrm{Ma}$ ) the crust may be coupled with the mantle. (b) Stress distributions for different gradients of bending stress and strain rates (500 Ma lithosphere). (Left) Concave downward bending (compression at the surface); (Right) concave upward bending (extension at the surface). The light grey area is the deviatoric stress for a moderate plate curvature; the darker grey area is that for the high curvature. Note the trend of the position of the neutral planes with increase of the stress gradient (light vertical arrows). The shape of the plate (exaggerated) is shown with thick-dashed curves. Thin-dashed curves correspond to strain rates from $10^{-13}$ to $10^{-17} \mathrm{~s}^{-1}$. Where the elastic bending stress reaches the yielding limits, the material becomes ductile or brittle. Even low flexural stress is enough to detach the crust from the mantle by creep at the crust-mantle boundary. At a higher flexure large portion of the lithosphere becomes inelastic. For nonzero topography load the surface strength is determined by the overburden lithostatic pressure. (c) Same as Figure $3 \mathrm{~b}$ but constant extensional horizontal force (horizontal stress of $200 \mathrm{MPa}$ ) is added. Dark grey area is the stress distribution in the plate subjected to the horizontal extensional force only. Light grey area is the stress after additional moderate bending. Note the change in the geometry of the brittle, elastic and ductile areas, and shift of the neutral planes. The compressional force would have a reversed effect, note also that the brittle areas are much stronger for compression than for tension. 

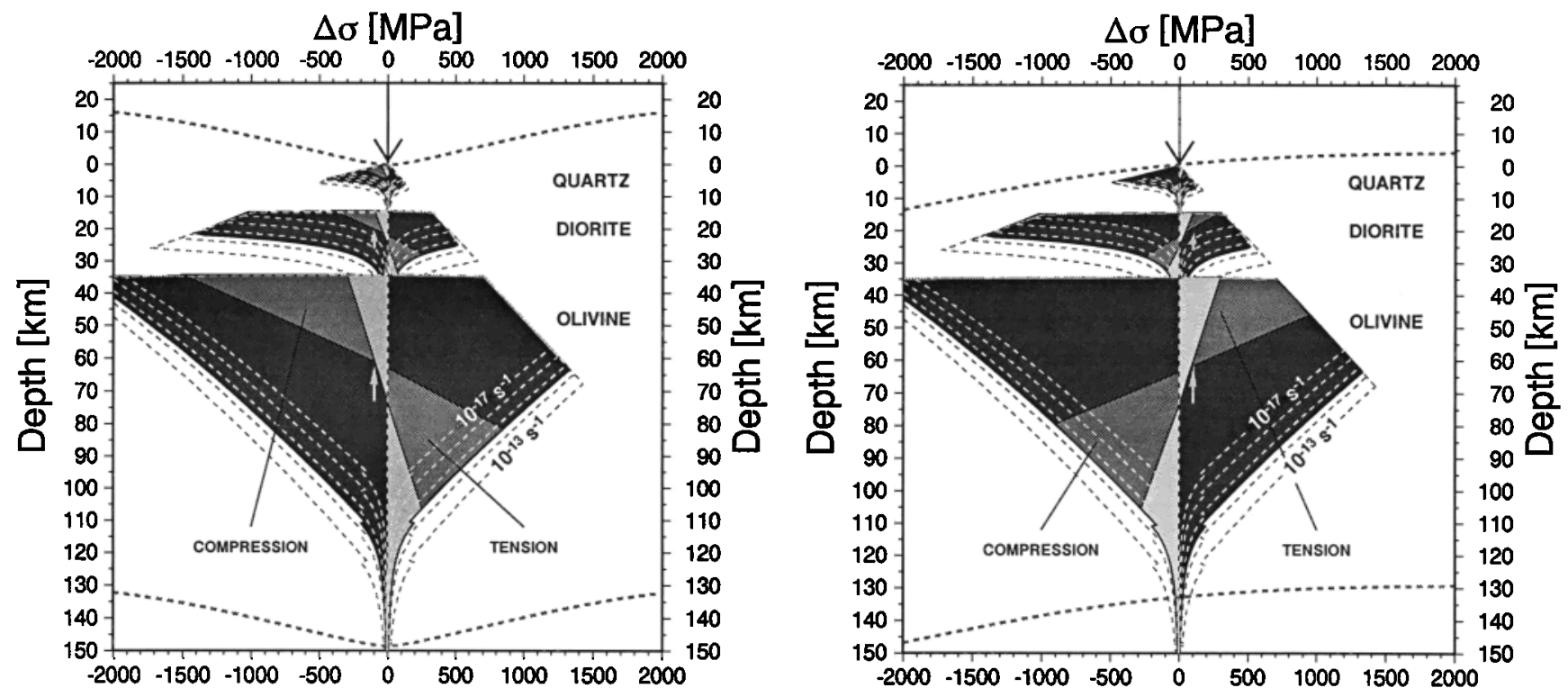

Figure 3b
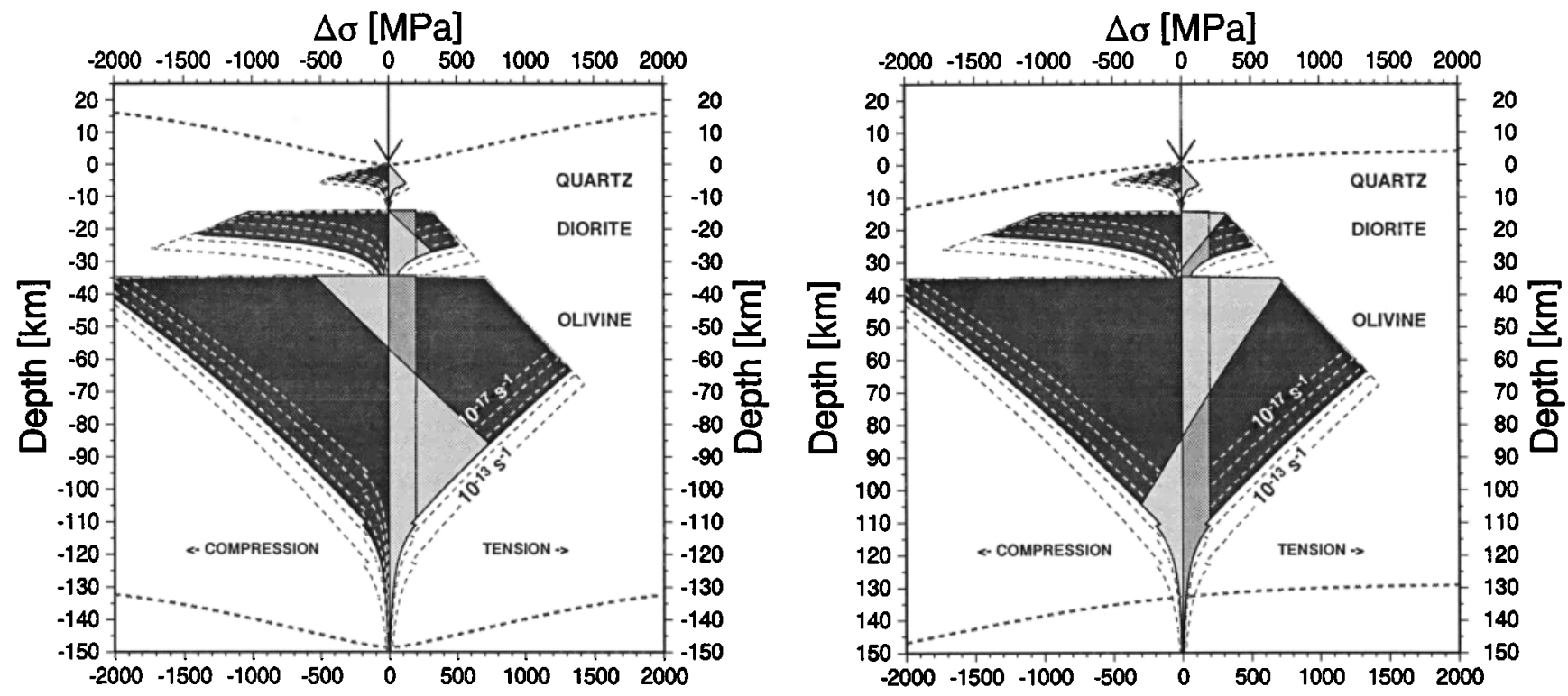

Figure 3c

takes place in most cases, except for very old cold lithosphere (> $750 \mathrm{Ma}$ ). The differences in the mechanical properties of the crust and mantle are related to variations in the mineral composition (e.g., quartz, diabase or quartz-diorite, Figure 3a), presence of fluids (wet/dry rheology), porosity, and so on. Other independent data provide additional constraints on the choice of rheology. These data include seismicity distributions associated with brittle failure [Meissner and Tapponnier, 1982; Chen and Molnar, 1983; Cloetingh and Banda, 1992; Govers et al., 1992; Déverchère et al., 1993]; anomalies of seismic velocity, reflectivity and attenuation supposedly associated with ductile zones [e.g., Kusznir and Matthews, 1988; Wever, 1989], petrology data [Cloetingh and Banda, 1992], and data from magnetotelluric soundings (indicators of the presence of melts and fluids [Berdichevsky et al., 1982; M. N. Berdichevsky, personal communication, 1994], etc. Here we also show that $T_{e}$ estimates, thermotectonic age, plate curvature, and Moho depth can be used to constrain the rheology. The possibility of crust-mantle decoupling suggests the presence of flow in the weak lower crust with associated effects like dissipative heating [Lobkovsky, 1988; Kruse et al., 1991; Lobkovsky and Kerchman, 1992; Burov et al., 1993].

Age (temperature) and activation energy. The lithosphere strengthens when it gets colder with age (Figure 3a), as well as when it is deformed with higher strain rates (Figure 3b). However, there is no direct relationship between the depth-temperature $\left(y-T\right.$, or better to say, $\left.y-H^{*} / R T\right)$ distribution and the geological age of the lithosphere at time of loading. Indeed, plates may undergo thermal resettings that completely change their actual thermal state (e.g., Kazakh shield [Burov et al., 1990], Adriatic lithosphere [Kruse and Royden, 1994]). After some time (>750$1000 \mathrm{Ma}$ or even $>400 \mathrm{Ma}$, Figure 2) the temperature distribution in the lithosphere approaches a stationary state and practically does not evaluate anymore. 
We use the term "thermal age" (see appendix) to discriminate from the true geological age. The thermal age $(t)$ controls the depth to a specific geotherm obtained from the plate cooling model assuming that the lithosphere did not undergo thermal resettings during this time (appendix, Figure 2). Therefore the thermal age gives the age of the last large-scale thermal event. In the absence of such events it coincides with the geological age (e.g., Siberian craton, Tarim basin). The thermal age allows us to specify lithospheric geotherm, and it also provides a lower bound on the true age of the lithosphere. Use of the surface heat flux in continental domains is less convenient because there it is too "polluted" by upper crustal heat generation and superficial thermal effects due to erosion and sedimentation. Therefore it mainly reflects crustal processes and should not be used to infer directly the subcrustal geotherm [England and Richardson, 1980]. However the surface heat flux is still useful to constrain the crustal geotherm [Jaupart, 1983].

The base of the mechanical lithosphere in continents is referred to the depth at which the yielding stress is less than 10-20 $\mathrm{MPa}$, that is the depth to the isotherm $700^{\circ} \sim 750^{\circ} \mathrm{C}[\mathrm{McNutt}$ et al., 1988]. The depth to this geotherm is defined from the thermal model of the lithosphere (see appendix), and can be additionally constrained from the heat flux data, seismic data and from inversion of the middle- and long-wavelength magnetic anomalies (this allows to define the depth to Curie's temperature $600^{\circ} \mathrm{C}$ [Achache et al., 1994]). However, we avoid prescribing some fixed values for the minimum sensitive deviatoric stress but make it dependent on the lithostatic pressure, for example. We thus prefer to define the depth to the mechanical base of the lithosphere as the depth where the yielding stress becomes negligible compared to the lithostatic pressure $(1-5 \%$ of the lithostatic pressure at the depth to the isotherm $700^{\circ}-800^{\circ} \mathrm{C}$ ). It is also sensible to relate the base of the mechanical lithosphere to some minimum sensitive value of the vertical gradient of yielding stress (say, 10-15 $\mathrm{MPa} / \mathrm{km}$ ). If the uncertainties in age/temperature are about $10-20 \%$, the uncertainties in determination of the depth to the mechanical base of the mantle lithosphere will be only about 5-10\% (Figure 3a). The same applies to the base of the mechanical crust (isotherm $300^{\circ}-400^{\circ} \mathrm{C}$ for quartzites). Note also (equation (lb)), that the yield stress is proportional to the $1 / n$ power of the strain rate divided by the material constant and $\exp \left(-H^{*} / R T\right)$. Keeping in mind that $n$ is $\sim 3$, this means that the uncertainty in the determination of the stress is roughly proportional to the cubic root from the uncertainties in $A^{*}, \dot{\varepsilon}$, and $\exp \left(-H^{*} / R T\right)$. Thus $10-20 \%$ uncertainty in the above parameters will lead to only few percent uncertainty is the stress.

Strain rate. Figure $3 b$ shows dependence of the $Y S E$ on the strain rate. The basic strain rates are typically known within the accuracy of 1 order. As seen from Figure 3b, such uncertainty in estimation of the strain rate will change the yielding limits by no more than $10 \%$. Three orders of variation of the strain rate will result in only 1 order of variation of the yielding stress for dislocation creep [e.g., Hopper and Buck, 1993].

\section{Mechanical Model for Nonlinear Flexure}

Deformation of an inelastic medium (plastic, viscous-elastic) can be described as deformation of an elastic medium with timespace variable elastic properties. This approach, known as the method of elastic solutions, is commonly used in applied mechanics [e.g., Alexandrov and Potapov, 1990]. Deflection of an inelastic (brittle-elasto-ductile) plate can be modeled as deflection of some equivalent elastic plate with space-variable $T_{e}$. However, such effective $T_{e}$, valid only for the instantaneous, or static plate geometry, may yield only correct strains but not necessarily stresses, and it will vary with changes in the plate geometry or in the distribution of loads.

\section{Plate Equilibrium Equations in Rheology Independent Form}

In a most general case a summary force applied to a volume $V$ of a deforming body is $\int F d V$, where $F$ is a force acting on a unit volume. Each of the three components of the force $\int F_{t} d V$ can be expressed as $\int F_{i} d V=\int \partial \sigma_{i k} / \partial x_{k} d V$, where $\sigma_{i k}$ is a stress tensor. Correspondingly, the moment of force $\mathbf{F}$ is [Fr], where $\mathbf{r}$ is the radius-vector defined by the coordinates $x_{i}$ of a point to which the force is applied. The moment of all forces acting on the volume $d V$ is [Landau and Lifchitz, 1987]:

$$
M_{i k}=\int\left(F_{1} x_{k}-F_{k} x_{1}\right) d V=\int\left(\frac{\partial \sigma_{i l}}{\partial x_{l}} x_{k}-\frac{\partial \sigma_{k l}}{\partial x_{l}} x_{i}\right) d V
$$

This basic expression is rheology independent and thereby is valid for elastic and inelastic rheology. Assuming a Cartesian $x y z$ coordinate system, let plane $x z$ be horizontal, axis $x$ be directed to the right, and $y$ be downward positive. In the case of flexure of a plate, the vertical deflection of the plate depends only on two coordinates, $x$ and $z$ in our case. Most models of lithospheric flexure use cylindrical (plain strain) bending assuming that the plate is infinite in one direction [e.g., Watts and Talwani, 1974; Forsyth, 1980; McNutt, 1980; Lyon-Caen and Molnar, 1983; Sheffels and McNutt, 1986; Watts, 1988; Judge and McNutt, 19911. Let the plate be infinite in the $z$ direction, then the strain component $\varepsilon_{2 z}$ along the axis $z$, normal to $x y$ plane, is zero $\left(\varepsilon_{z z}=0\right)$. In this case the bending moment $M=M_{x}$, horizontal (longitudinal) force component $T_{x}$ and vertical (shearing) force component $F_{x}$ per unit width of the plate is expressed as follows:

$$
\begin{gathered}
M_{x}=-\int_{0}^{\infty} \sigma_{x x}\left(y-y_{n}\right) d y=-\int_{0}^{h} \sigma_{x x}\left(y-y_{n}\right) d y \\
T_{x}=-\int_{0}^{\infty} \sigma_{x x} d y=-\int_{0}^{h} \sigma_{x x} d y \\
F_{x}=-\int_{0}^{\infty} \sigma_{x y} d y=-\int_{0}^{h_{2}} \sigma_{x y} d y=\frac{\partial M}{\partial x}
\end{gathered}
$$

where $y_{n}$ is the depth to the neutral plane of the plate (single neutral plane is assumed in (8)). The upper limit $h_{2}$ corresponds to the depth at which the longitudinal stress $\sigma_{x x}$ and shear stress $\sigma_{x y}$ become negligible: $\lim _{y \rightarrow h_{2}}\left(\sigma_{x x} / p\right.$

$\left.\sigma_{x y} / p\right)=0$, where $p$ is lithostatic pressure. Thus in a general case the value of $h_{2}$ is equivalent to the depth at which lithospheric materials become so weak that they can only support negligibly low deviatoric stresses (stress of $<10-20 \mathrm{MPa}$ is commonly used as a sensitivity limit [Ranalli, 1994]). Thus, according to our definition, $h_{2}$ is the depth to the base of the mechanical lithosphere.

The equation of static equilibrium of a thin plate [Timoshenko and Woinowsky-Krieger, 1959], derived from (8) is rheology independent and thus holds for elastic, plastic, viscous, ductile or mixed rheology:

$$
-\frac{\partial^{2} M_{x}}{\partial x^{2}}+\frac{\partial}{\partial x}\left(T_{x} \frac{\partial w}{\partial x}\right)+p_{-}=p_{+}
$$

where $w=w(x)$ is the vertical deflection of the plate, $p_{-}$is the buoyancy restoring force per unit area

$$
p_{-}=g \int_{h_{2}}^{h_{2}+w(x)} \rho_{m}(x, y) d y-g \int_{h}^{h_{c}+w(x)} \rho_{c}(x, y) d y \approx g w(x)\left(\rho_{m}-\rho_{c}\right),
$$


$\rho_{m}(x, y)$ and $\rho_{c}(x, y)$ are the respective densities of the mantle and crustal material $\left(\rho_{m}=3330 \mathrm{~kg} / \mathrm{m}^{3}\right.$ and $\rho_{c}=2670 \mathrm{~kg} / \mathrm{m}^{3}$ are their typically inferred average values), $g$ is the acceleration due to gravity, $h_{c}$ is the thickness of the crust. The additional vertical force $p_{+}$is defined as the sum of topographic loads and effective vertical forces $f_{a}(x)$ associated with plate-boundary forces. These forces result from plate collision, interaction with the convecting mantle, buried loads, and sediments. Thus

$$
p_{+}=g \int_{0}^{-h} \rho_{s}(x, y) d y+f_{a}(x),
$$

where $h=h(x)$ is the topography elevations (negative above the sea level) and $\rho_{s}(x, y)$ is the density of the material above the reference sea level.

The above equilibrium equations are valid within certain limits imposed by geometrical simplifications made for their derivation. These simplifications are thin plate approximation, the assumption of cylindrical bending, and the assumption of small plate deflections. The thin plate approximation neglects the effect of bending of normal and shearing stresses. Thus it holds only when the thickness of the plate is much less than its length, and essentially less than the radius of the plate curvature $R_{x y}$ The assumption of cylindrical bending implies that plane cross sections of a plate subjected to bending remain plane and normal to the neutral plane. Plate deflection has to be independent of the coordinate $z$. Finally, plate deflection has to be small compared to the thickness of the plate (all points of the neutral plane(s) displace only in the direction of the vertical $(y)$ axis.)

At a first glance, the assumption of cylindrical bending might be a crude approximation for the continental lithosphere. However, the radius of curvature of the arc front $\left(R_{x z}\right)$ of most continental thrust belts is much larger than the maximum possible values of $h_{2}\left(h_{2}<130-140 \mathrm{~km}\right.$, Figure 2 , whereas $R_{x z}>350 \mathrm{~km}$ [McNutt et al., 1988; Ranalli, 1994]). This allows us to neglect plate bending in the plane of the surface of the Earth ( $x z$ plane) when predominant bending in the vertical $(x y)$ plane occurs. Anyway, we have to keep in mind, that the values of $R_{x z}$ bound the radius of plate curvature in the vertical plane $\left(R_{x y}\right)$ [Timoshenko and Woinowsky-Krieger, 1959]. This also applies to the radius of plate curvature in $y z$ plane, which should be greater than $R_{x z}$ and $h_{2}$ as well. All available direct estimates of $T_{e}$ (Figure 2 ) are obtained within these assumptions. Therefore we can use them to test the compatibility of our theoretically predicted values of $T_{e}$ with the direct estimates.

\section{Dependence on Rheology in Plate Equilibrium Equations}

The dependence of plate equilibrium equations on rheology "plugs in" only at the stage when one has to specify the functions $M_{x}$ and $T_{x}$ in (9). Indeed, this requires us to define the materialdependent relationships between the internal stress components $\left(\sigma_{x x}, \sigma_{x y}, \sigma_{y y}\right)$ and the strain components $\left(\varepsilon_{x x}, \varepsilon_{x y}, \varepsilon_{y y}\right)$ (see the previous section).

Pure elastic rheology: Single layer plate. The elastic plate approximation assumes $\sigma_{x x}=\sigma_{x x}^{e}=\varepsilon_{x x} E\left(1-v^{2}\right)^{-1}$, where, for a single-layer plate, $\varepsilon_{x x}=E^{-1}\left(\sigma_{x x}-v \sigma_{y y}\right) \approx$ $\left(y-T_{e} / 2\right) \partial^{2} w(x) / \partial x^{2}$. Assuming single layer elastic model for the lithosphere, one has to expect that $h_{2}$ strictly correlates with the effective elastic thickness $T_{e}$. However, as shown in Figure 2, this holds only for a few cases. Indeed, in terms of the elastic plate approximation it is difficult to provide a physically consistent interpretation for $h_{2}$, since the deviatoric stresses $\sigma_{x x}^{e}$ in the elastic plate monotonically grow with distance from the neutral plane, reaching maximum absolute levels at the upper $(y=0)$ and bottom $\left(y=T_{e}\right)$ surfaces of the plate:

$$
\begin{gathered}
\sigma_{x x}^{e} \approx \gamma\left(y-T_{e} / 2\right) \Rightarrow \max _{y}\left|\sigma_{x x}\right|=\left|\sigma_{x x}\right|_{y=\left\{0 ; T_{e}\right\}}|=| \gamma \mid T_{e} / 2 \\
-M_{x}(x)=\int_{-T_{e} / 2}^{T_{e} / 2} \sigma_{x x} y d y=\frac{\gamma T_{e}^{3}(x)}{12}=-D(x) \frac{\partial^{2} w(x)}{\partial x^{2}}
\end{gathered}
$$

where $\gamma \equiv \partial \sigma_{x x}(x, y) / \partial y \approx E\left(1-v^{2}\right)^{-1} \partial^{2} w(x) / \partial x^{2}$ is the vertical gradient of the elastic deviatoric stress. The flexural rigidity $D(x)$ and $T_{e}=T_{e}(x)$ are functions of coordinate only and do not depend on the vertical deflection $w$ and its spatial derivatives, as well as on the strain and stress. The properties of the elastic plate, defined through the variable parameters $M_{x}=M_{x}(x)$ and $T_{x}=T_{x}(x)$, are also independent of stress and strain.

Arbitrary rheology: Composite plate with nonlinear properties and self-adjusting layering. For inelastic rheology the expressions for $M_{x}$ and $T_{x}$ can be derived from (8) in the same way as for the elastic rheology. The only difference is that the operators relating stress and strain will be defined through the nonlinear expression (5), constructed from constitutive equations (1)-(3) and (4).

Continental plates may exhibit horizontal mechanical discontinuities or low strength zones. For example, a weak lower crust that cannot support significant bending stresses (Figure 3) may allow a strong upper crust to deform independently of the uppermost mantle lithosphere. The competent layers, separated by such weak zones, are no longer "welded" together, similar to the leaves of a laminated spring. In this case horizontal components of stress cannot be transmitted from one competent layer to another (upper crust and mantle). The lithosphere thus deforms as a system of distinct "subplates" with separate neutral planes [Lobkovsky and Kerchman, 1992]. The bending moment $M_{x}$ for a system with $n$ neutral planes is

$$
M_{x}=-\sum_{i=1}^{n} \int_{y_{i}^{-}(x)}^{y_{i}^{+}(x)} \sigma_{x x}(x, y) y_{i}^{*}(x) d y
$$

where $y_{i}^{*}=y-y_{n i}(x), y_{n i}$ is the depth to the $i$ th neutral plane $\left(\left.\sigma_{x x}\right|_{y_{i}^{*}=0}=0\right) ; y_{i}^{-}(x)=y_{i}^{-}, y_{i}^{+}(x)=y_{i}^{+}$are the respective depths to the lower and upper low-strength interfaces. Correspondingly, the thickness of the $i$ th detached layer is $y_{i}^{+}-y_{j}^{-}=\Delta h_{i}(x)$.

In addition, the material properties may also vary continuously within each discrete layer. The expression for $M_{x}$ thus becomes

$$
M_{x}=-\sum_{i=1}^{n} \sum_{j=1}^{m_{i}} \int_{y_{j j}^{-}(x)}^{y_{i j}^{+}(x)} \sigma_{x x}^{(J)}(x, y) y_{j}^{*}(x) d y
$$

where $m_{i}$ is a number of "welded" (continuous $\sigma_{x x}$ ) sublayers in the $i$ th detached layer:

$$
\left.\sigma_{x x}^{(j)}(x, y)\right|_{y_{y}^{-}(x)}=\left.\sigma_{x x}^{(j-1)}(x, y)\right|_{y_{i(j-1)}^{+}(x)},
$$

$\sigma_{x x}^{(j)}(x, y)=\sigma(\varepsilon)$ is the bending stress defined for material parameters of $j$ th sublayer belonging to the $i$ th detached layer, $j=j(i)$. For example, for an elastic sublayer we have

$$
\begin{gathered}
\sigma_{x x}^{(j)}(x, y)=\varepsilon_{x x}(x, y) E_{j}(x) /\left(1-v_{j}^{2}(x)\right) \approx \\
y_{i}^{*} w_{x x}^{\prime \prime} E_{j}(x) /\left(1-v_{j}^{2}(x)\right)=\gamma_{j}(x) y_{i}^{*}
\end{gathered}
$$

Interiors of layers with nonlinear rheology and mixed composition obey brittle, elastic, or ductile constitutive laws according to the principle of minimal yield stress (4)-(5). As stated above, this minimum depends on various local conditions such as temperature, stress gradient, pressure, mineral composition, and other specific features. These conditions determine as well the 
geometry and dimensions of the brittle, elastic, and ductile zones delineated by the rheological interfaces $y_{i j}^{-}(x), y_{i j}^{+}(x)$ (Figures $3 \mathrm{~b}$ and 3c, [McAdoo et al., 1985; Burov and Diament, 1992]). Therefore $y_{i j}^{-}(x), y_{i j}^{+}(x)$, and $y_{n i}$ depend not only on $x$ and $i$ but also on the local gradient of deviatoric stress $\gamma_{i j}(x, y)$ and the lithostatic pressure $p$ :

$$
p \approx \int_{0}^{(y+w(x)-h(x))} g \rho(x, y) d y,
$$

where $\rho(x, y)=n(x, y) \rho_{f}(x, y)+(1-n(x, y)) \rho_{g}(x, y)$ is the bulk density, $n$ is porosity, $\rho_{f}$ is a density of pore fluid, and $\rho_{g}$ is a density of solid grain, $h(x)$ is negative above the sea level. The geometry and location of the rheological interfaces are not tied to some predefined levels within the plate, as in the pure elastic case, but evolve with the deformation (Figures $3 b$ and $3 c$ ). The elastic behavior is associated with the highest strength. When bending stresses due to the flexure of the plate reach local yielding limits, zones of inelastic (brittle or ductile) behavior appear. This lowers the local integrated strength of the plate. As a result the plate bends as if it has effectively lower $T_{e}$ in zones of higher curvature. In other words, the local mechanical properties of the plate change to adopt strains and stresses caused by plate deflection $w=w(x)$. The parameters $M_{x}$ and $T_{x}$ in (9) thus become functions of $w(x)$ and its derivatives $\left(w^{\prime}=\partial w / \partial x ; w^{\prime \prime}=\partial^{2} w / \partial x^{2}\right.$; $M_{x}=M_{x}\left(x, y, w, w^{\prime}, w^{\prime \prime}\right) ; T_{x}=T_{x}\left(x, y, w, w^{\prime}, w^{\prime \prime}\right)$ :

$$
\begin{gathered}
\tilde{M}_{x}\left(x, y, w, w^{\prime}, w^{\prime \prime}\right) \equiv \tilde{M}_{x}(\phi)=-\sum_{i=1}^{n} \sum_{j=1}^{m_{1}} \int_{y_{i j}^{-}(\phi)}^{y_{v j}^{+}(\phi)} \sigma_{x x}^{(j)}(\phi) y_{i}^{*}(\phi) d y \\
\tilde{T}_{x}\left(x, y, w, w^{\prime}, w^{\prime \prime}\right) \equiv \tilde{T}_{x}(\phi)=-\sum_{i=1}^{n} \sum_{j=1}^{m_{1}} \int_{y_{i j}^{-}(\phi)}^{y_{i j}^{+}(\phi)} \sigma_{x x}^{(j)}(\phi) d y
\end{gathered}
$$

where $\phi \equiv\left\{x, y, w, w^{\prime}, w^{\prime \prime}\right\}, \sigma_{x x}^{(j)}(\phi)=\sigma(\varepsilon)=\sigma_{x x}^{(j)} U_{-}\left(\left|\sigma^{f}(\varepsilon)\right|-\left|\sigma_{x x}^{(j)}\right|\right)$ is

the stress in $i$ th rheological zone of the plate, defined accordingly to (1)-(3), (4), and (5). The expression for $\sigma(\varepsilon)$ is given by (5); $\sigma^{f}(\varepsilon)$ is the $Y S E$ defined by (4), and $U_{-}$is a step function such as $U_{-}(f)=0$ if $f \leq 0$, and $U_{-}(f)=1$ if $f>0$. The equilibrium equation (9) is now nonlinear and can be only solved numerically.

Equations (10) reflect two major characteristics of the nonlinear lithosphere: division onto fixed layers (their thickness is independent of strain and stress), and onto layers with variable, adoptive thickness that depends of the stress/strain distribution. The division onto fixed layers is determined by the piecewise continuous lithological structure of the lithosphere consisting of the upper, middle, and lower crustal layers (e.g., quartz, quartz-diorite, diabase, respectively) and of the upper mantle layer (olivine). This layering is simply determined by which specifical mineral composition controls the mechanical properties of the lithosphere at a given depth (this is described by the index $j=j(i)$ of the material parameter set $i j$, for example, 11 for quartz, 12,22 for diabase ... 31 for olivine. Here $i=1$ for the upper crust, $i=2$ for the lower crust, $i=3$ for the mantle, $j(1)=1$ for the quartz, $j(1)=2, j(2)=2$ for the diabase, $j(3)=1$ for the olivine.) Naturally, the lithological layering does not depend on plate flexure (excluding phase transitions that might be dependent on differential stress as well as on the change in $P T$ conditions caused by plate deflection). The geometry of the brittle, ductile, and elastic zones is stress and strain-dependent, resulting in adoptive layering onto brittle, ductile and elastic sublayers, defined by strain- and stress-dependent functions $y_{i j}^{-}(\phi), y_{i j}^{+}(\phi)$.
To estimate the effective rigidity of the plate with non-linear rheology, we introduce a nonlinear rigidity function $\tilde{D}=\tilde{D}(\phi)$ such as

$$
\tilde{D}(\phi) \frac{\partial^{2} w(x)}{\partial x^{2}} \approx-\tilde{D}(\phi) R_{x y}^{-1}=-\tilde{M}_{x}(\phi)
$$

Accordingly we now define the effective elastic thickness $\tilde{T}_{e}=\tilde{T}_{e}(\phi)$ as

$$
\tilde{T}_{e}^{3}=\frac{\tilde{D}(\phi)}{D_{0}}=\frac{-\tilde{M}_{x}(\phi) R_{x y}}{D_{0}} \approx \frac{\tilde{M}_{x}(\phi)}{D_{0}}\left(\frac{\partial^{2} w(x)}{\partial x^{2}}\right)^{-1}
$$

where $D_{0}=E\left(12\left(1-v^{2}\right)\right)^{-1}$ and $R_{x y} \approx-\left(w^{\prime \prime}\right)^{-1}$ is the radius of plate curvature. The effective rigidity $D$ and effective elastic thickness $T_{e}$ can be obtained from solution of the following system:

$$
\begin{gathered}
\frac{\partial}{\partial x}\left(\frac{\partial}{\partial x}\left(D_{0} \tilde{T}_{e}^{3}(\phi) \frac{\partial^{2} w(x)}{\partial x^{2}}\right)+\tilde{T}_{x}(\phi) \frac{\partial w(x)}{\partial x}\right)+p_{-}(\phi) w(x)=p_{+}(x) \\
\tilde{T}_{e}(\phi)=\left(\frac{\tilde{M}_{x}(\phi)}{D_{0}}\left(\frac{\partial^{2} w(x)}{\partial x^{2}}\right)^{-1}\right)^{\frac{1}{3}} \\
\tilde{M}_{x}(\phi)=-\sum_{i=1}^{n} \sum_{j=1}^{m_{i}} \int_{y_{i j}^{-}(\phi)}^{y_{i j}^{+}(\phi)} \sigma_{x x}^{(j)}(\phi) y_{i}^{*}(\phi) d y \\
\tilde{T}_{x}(\phi)=-\sum_{i=1}^{n} \sum_{j=1}^{m_{i}} \int_{y_{i j}^{-}(\phi)}^{y_{j}^{+}(\phi)} \sigma_{x x}^{(J)}(\phi) d y
\end{gathered}
$$

The integrals in (13) are defined through the constitutive laws (1)-(3) and (4)-(5) relating stress $\sigma_{x x}$ and strain $\varepsilon_{x x}=\varepsilon_{x x}(\phi)$ for a plate segment $\{x, y\}$. The value of the unknown function $\tilde{T}_{e}(\phi)$ (or of the effective flexural rigidity $\tilde{D}(\phi)$ ) satisfying $(11)-(13)$, is equivalent to an instantaneous effective elastic thickness (or rigidity, respectively). It is important to note that it is valid only for the current deflection $w$. $\tilde{T}_{e}(\phi)$ (or $\tilde{D}(\phi)$ ) is thus strongly flexure dependent. The effective flexural strength $\left(T_{e}\right)$ of the lithosphere and the mechanical state (brittle, elastic, or ductile) of its inner zones depend on deviatoric stresses caused by local deformation. The stresses at each level are constrained by the $Y S E$, defined by the expressions (4)-(5) (see also Figures $3 \mathrm{~b}$ and 3c. Note migration of neutral planes at higher flexure and horizontal stress). Resulting interdependence between the local strength and plate structure is highly nonlinear negative feedback. The system becomes self-organizing which justifies a numerical approach. To solve system (13) we use an iterative approach based on finite difference approximation (block matrix presentation) with linearization by Newton's method [ $\mathrm{Na}, 1979]$. The procedure starts from elastic prediction that gives predicted $w_{e}(x), w_{e}^{\prime}(x), w_{e}^{\prime \prime}$, used to find subiteratively solutions for $y_{y}^{-}(\phi), y_{t j}^{+}(\phi)$, and $y_{m t}(\phi)$ that satisfy $(10)$ and (1)-(3). This gives corrected solutions for $\tilde{M}_{x}$ and $\tilde{T}_{x}$ which are used to obtain $\tilde{T}_{e}$ for the next iteration. At this stage we use gradual loading technique to avoid oscillations. The accuracy is checked directly on each iteration, through back-substitution of the current solution to (9) and calculation of the discrepancy between the right and left sides of (9). For the boundary conditions we use typical combination of plate-boundary shearing force $F_{x}(0)$ and plate boundary moment $M_{x}(0)$ [e.g., Sheffels and McNutt, 1986], at the near end of the plate, and $w=0, w^{\prime}=0$ at the far end. In addition to our calculations made on the basis of plate approximation we also tested our results using the finite element code 
"Tecton" (v. 1.51) kindly provided by J. Melosh [e.g., Melosh and Williams, 1989]. This code allows to solve force/momentum, continuity and constitutive equations for large deformations of an arbitrarily shaped visco-elastic body. Although this code does not allow to incorporate the "true" brittle-elasto-ductile rheology, we used it to test the validity of the geometric constraints imposed by the thin plate approximation for different specific cases (next section). Comparing expression (6) for lithospheric strength $(B)$ with the expressions (8) and (11), one can see that the effective elastic rigidity $D$ (or the effective elastic thickness $T_{e}$ ) is equivalent to instantaneous integrated strength of the plate.

\section{Results of Modeling and Discussion}

In this section we investigate major factors controlling the effective elastic thickness of the lithosphere. We compare existing $T_{e}$ estimates for different regions with model predictions. We investigate the influence of factors such as the load of the topography, the plate curvature and the crustal composition.

\section{$T_{e}$ and Crust-Mantle Coupling and Decoupling}

It has been suggested that variations in the composition and thickness of the crust may result in decoupling (low-temperature activated lower crust and/or thick crust) or coupling (more "basic," high-temperature activated crust and/or thin crust) of the crust with the mantle lithosphere. Although the second possibility is a matter of separate discussions [Stephenson and Cloetingh, 1991; Burov et al., 1993], we address both cases to clarify which crustal composition is most adequate to available $T_{e}$ estimates. We focus on the observed $T_{e}$ derived for continental lithosphere overridden by thrust belts at active or extinct plate boundaries and post-glacial rebound data in order to avoid variability in $T_{e}$ arising from badly constrained thermal events associated with rifting and extension. Rifts and volcanic areas are generally characterized by low $T_{e}$ [e.g., Ebinger et al., 1989] due to thermal weakening and necking of the lithosphere. Finally, we do not consider here possible preexisting mechanical heterogeneities.

If the lower crust and mantle are mechanically coupled, the continental lithosphere will deform as a single plate, similar to the oceanic lithosphere. In this case $T_{e}$ should monotonically depend on temperature and thus should approximately correspond to the depth to the base of the mechanical lithosphere $\left(h_{2}\right)$, associated with the isotherm $700^{\circ}-750^{\circ} \mathrm{C}$ (Figure 2). Only few estimates of $T_{e}$, mainly for old cold lithospheric plates (e.g., Appalachians), satisfy this condition (Figure 2). The majority of estimates of $T_{e}$ are much smaller than the depth to the $700^{\circ}$ $750^{\circ} \mathrm{C}$ geotherm. Young lithosphere (e.g., Alps) is an extreme example, because there $T_{e}$ estimates $(5-30 \mathrm{~km})$ are even smaller than the depth to the base of mechanically strong upper crust $\left(h_{1}\right)$, corresponding to the isotherm $200^{\circ}-300^{\circ} \mathrm{C}$ (Figure 2). The yield-stress envelopes from Figure 3 suggest that in most cases the crustal and mantle portions of the lithosphere can be decoupled from each other. The crust-mantle decoupling results in a drastic reduction (around 2 times) of the total effective strength of the lithosphere [McNutt et al., 1988; Burov and Diament, 1992]. This effect can be demonstrated by analogy with a simple multilayer elastic plate ("leaf spring" model). The effective elastic thickness of the plate, consisting of $\boldsymbol{n}$ detached (nonwelded) layers is

$$
T_{e}^{(n)}=\left(\sum_{i=1}^{n} \Delta h_{i}^{3}\right)^{1 / 3},
$$

where $\Delta h_{i}=y_{i}^{+}-y_{i}^{-}$is the effective elastic thickness of the $i$ th layer. For example, the total elastic thickness $\left(T_{e}\right)$ of a decoupled two-layer $(i=1,2)$ lithosphere with the base of the competent upper crust at depth $y_{1}^{-}=h_{1}$, the base of the competent mantle at depth $y_{2}^{-}=h_{2}$, and with the total thickness of the crust $y_{2}^{+}=h_{c}$, $h_{c}>h_{1}$ is [e.g., McNutt et al., 1988]:

$$
T_{e}=T_{e}^{(2)}=\sqrt[3]{h_{1}^{3}+\left(h_{2}-h_{c}\right)^{3}} \approx \max \left(h_{1},\left(h_{2}-h_{c}\right)\right)
$$

If the thickness of the competent crust $\left(h_{1}\right)$ is equal to the thickness of the competent mantle $\left(h_{1}=h_{2}-h_{c}\right)$, then $T_{e}^{(2)}=1.26\left(h_{2}-h_{c}\right)$; if $h_{h}$ is only half of the thickness of the competent mantle then $T_{e}^{(2)}=1.04\left(h_{2}-h_{c}\right) \approx h_{2}-h_{c}$.

For a coupled rheology $\left(h_{1} \geq h_{c}\right)$, the mechanical crust and mantle are "welded" together $\left(h_{1}=\min \left(h_{c}, h_{1}\right)\right)$, and the upper $T_{e}$ estimate is simply

$$
\begin{aligned}
& T_{e}=T_{e}^{c}=\left.\sum_{i=1}^{n} \Delta h_{i}\right|_{n=2}=h_{1}+h_{2}-h_{c}=h_{2} \\
& \text { (e.g., if } \left.h_{1}=0.5\left(h_{2}-h_{c}\right) \text { then } T_{e}^{c} \approx 2 * T_{e}^{(2)}\right)
\end{aligned}
$$

Note that $h_{1}$ and $h_{2}$ are defined as the depths at which the yielding strength is less than 10-20 MPa, or does not exceed $1-5 \%$ of the lithostatic pressure. Therefore $h_{1}, h_{2}$ do not exactly coincide with the depths to the isotherms $300^{\circ} \mathrm{C}$ and $750^{\circ} \mathrm{C}$, but also slightly depend on the slope of the $Y S E$ in the vicinity of these temperatures.

We investigated the idea of $T_{e}$ reduction by crust-mantle decoupling. For that we computed initial (maximum) $T_{e}$ of the lithosphere before loading (and bending), that is, for radius of plate curvature $\left(R_{x y}\right)$ greater than $10^{4} \mathrm{~km}$ (the radius of the Earth is $6378 \mathrm{~km}=10^{38} \mathrm{~km}$ ). Using (1)-(3), (5), and (12), we made these computations for all possible range of thermal age $(t)$ (appendix) and crustal thickness $\left(h_{c}\right)$. The predicted $T_{e}$ (Figure 4) has a strong "bimodal" behaviour, because for each value of the thermal age and given rheological parameters there is a critical or transitional value of crustal thickness $h_{c}=h_{c c}(t)$. The lithosphere is always decoupled when the crust is thicker than this value $\left(h_{c}>h_{c c}(t)\right)$, and coupled, when the crust is thinner $\left(h_{c}<h_{c c}(t)\right)$. This critical value corresponds to the transition zone in Figure 4b. It rapidly increases with the age of the lithosphere until it reaches an asymptotic value of $40 \pm 5 \mathrm{~km}$ for ages greater than $750 \mathrm{Ma}$. In the vicinity of this critical value the flexural strength may vary within $50-90 \%$. The sensitivity of $T_{e}$ to the critical crustal thickness can explain the bimodality of the distribution of $T_{e}$ estimates in the continents mentioned by Watts [1992]. Interestingly, the asymptotic value of the critical crustal thickness is close to the typical average thickness of the continental crust $(-40 \mathrm{~km})$. Note also the predicted weak dependence of $T_{e}$ on age for the old lithosphere (>750-1000 Ma), and that the asymptotic value of $T_{e}$ for an old lithosphere with a crustal thickness of $35-50 \mathrm{~km}$ is about $60-75 \mathrm{~km}$. For an old "coupled" lithosphere with thinner crust the value of $T_{e}$ is much larger, about $110 \mathrm{~km}$.

For very young lithosphere the thickness of the competent crust $h_{1}(x, t)$ may be greater than, or comparable with, the thickness of the competent mantle lithosphere $h_{2}(x, t)-h_{c}$. Consequently, the integrated strength of the young plate is controlled at a large extent by the strength of the crust [Kusznir and Karner, 1985, Figures 4a and 4b]. For example, Banda and Cloetingh [1992] suggested that the Moho temperature in the AlpineMediterranean area may reach in some places $800^{\circ} \pm 100^{\circ} \mathrm{C}$. Thus the mantle lithosphere perhaps does not contribute to the plate strength there. This probably explains why $T_{e}$ estimates for young and hot lithosphere rather follow the depths to the base of the mechanical crust (isotherms $200^{\circ}-300^{\circ}-400^{\circ} \mathrm{C}$ ), than the depths to the base of the mechanical lithosphere $\left(700^{\circ}-750^{\circ} \mathrm{C}\right)$ 
(Figure 2). As far as the lithosphere gets cooler with age, the strength of the mantle lithosphere grows faster than that of the crust. This occurs because after some time the geotherm corresponding to the base of the mechanical mantle $\left(700^{\circ}-750^{\circ} \mathrm{C}\right)$ is deepening faster than the geotherm corresponding to the base of the mechanical crust $\left(300^{\circ}-400^{\circ} \mathrm{C}\right.$, Figure 2). The different behavior of the geotherms is explained by that the crustal geo-

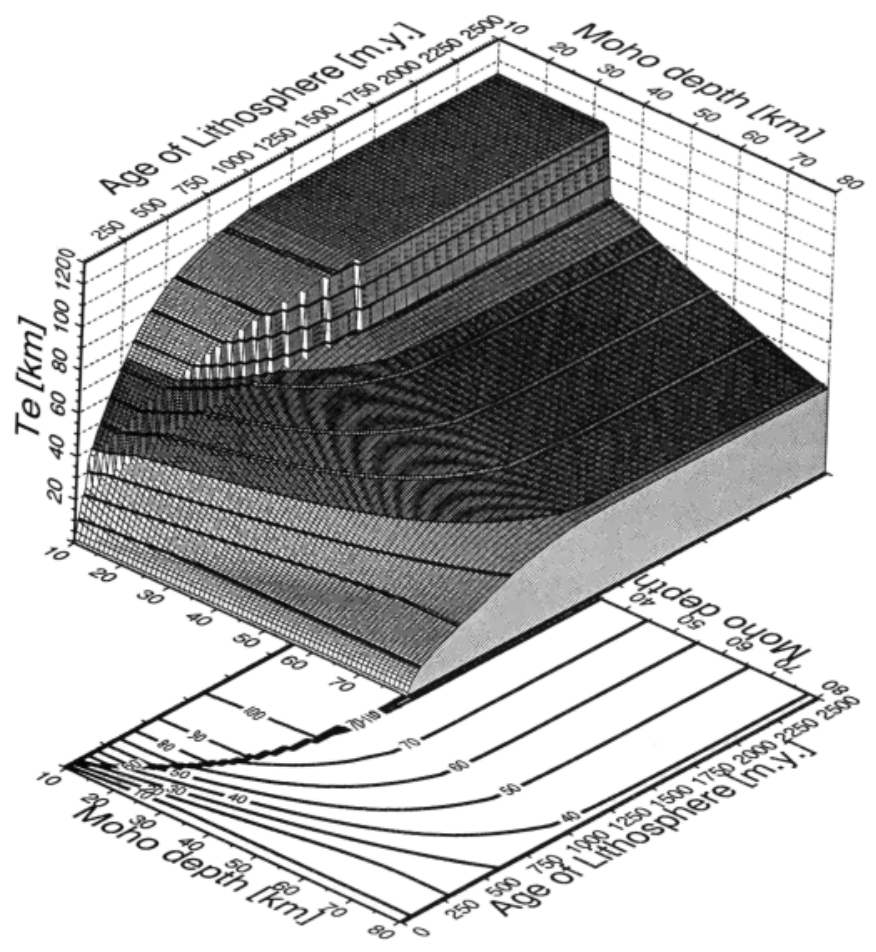

therms are closer to the surface and therefore faster stabilize their position, while deeper geotherms remain unsteady. In addition, the thermal regime of the crust is less time dependent than that of the mantle because of the nearly time invariant contribution of heat from the decay of radiogenic elements with long halflife periods that provide approximately half of the heat flux through the crust. The radiogenic heat production in the olivine/dunite upper mantle is much smaller ( $\sim 10$ times) than in the crust and can be neglected [Parsons and Sclater, 1977; Sclater et al., 1980; Turcotte and Schubert, 1982]. For ages larger than 100-150 $\mathrm{Ma}$, the lithospheric strength is significantly controlled by the strength of the mantle. Consequently, the upper limit on the strength of the lithosphere is determined not only by its thermal structure (as for oceans), but in an equal degree by the proportion between the thickness of the mechanical crust and the mantle, which varies in a complex way with age. To demonstrate this, we calculated $T_{e}$ (equation $(12)$ at $\tilde{M}_{x}(\phi) \rightarrow 0$, $w^{\prime \prime} \rightarrow 0$ ) as a function of age for different values of the crustal thickness (from 20 to $80 \mathrm{~km}$ ) and compared it with available $T_{e}$ estimates. The theoretical curves in Figure 5 show predicted $T_{e}$ for all possible values of crustal thickness $\left(h_{c}\right)$. For all observed

Figure 4a. Dependence of the maximum initial (preflexural) effective elastic thickness on the thermal age and crustal thickness for decoupled and coupled rheology. Three-dimensional perspective plot showing dependence of $T$, as function of crustal thickness and age. High elevated areas correspond to the coupled rheology, and low areas correspond to the decoupled rheology. The intermediate area is a "bifurcation" zone. This explains the observed bimodality in $T$, behavior [Watts, 1992]. Note that for very young lithosphere $(<\sim 100 \mathrm{Ma})$ there is practically no difference between the coupled and decoupled regime, since the mantle lithosphere is very weak.

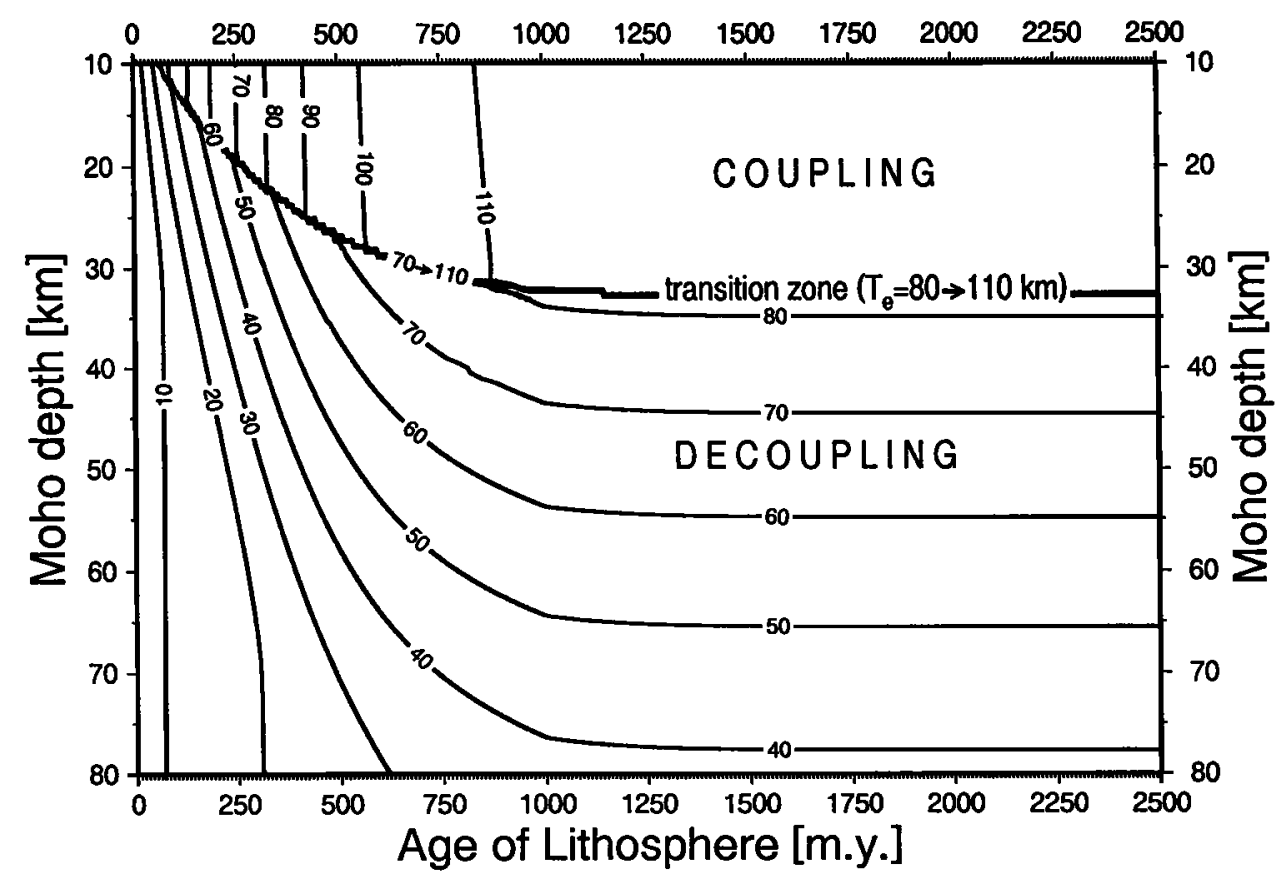

Figure 4b. Projection of Figure 4a on a plane. One can see that for each age there is a critical value of crustal thickness (curve marked transition zone). If the crustal thickness is larger than this critical value, the lithosphere is practically always decoupled, resulting in low $T_{e}$. In turn, thin crust results in mechanical coupling between the crust and mantle and in high $T$, values. For a lithosphere older than $750 \mathrm{Ma}$ the value of the critical crustal thickness is practically constant and equal to $35-40 \mathrm{~km}$. 


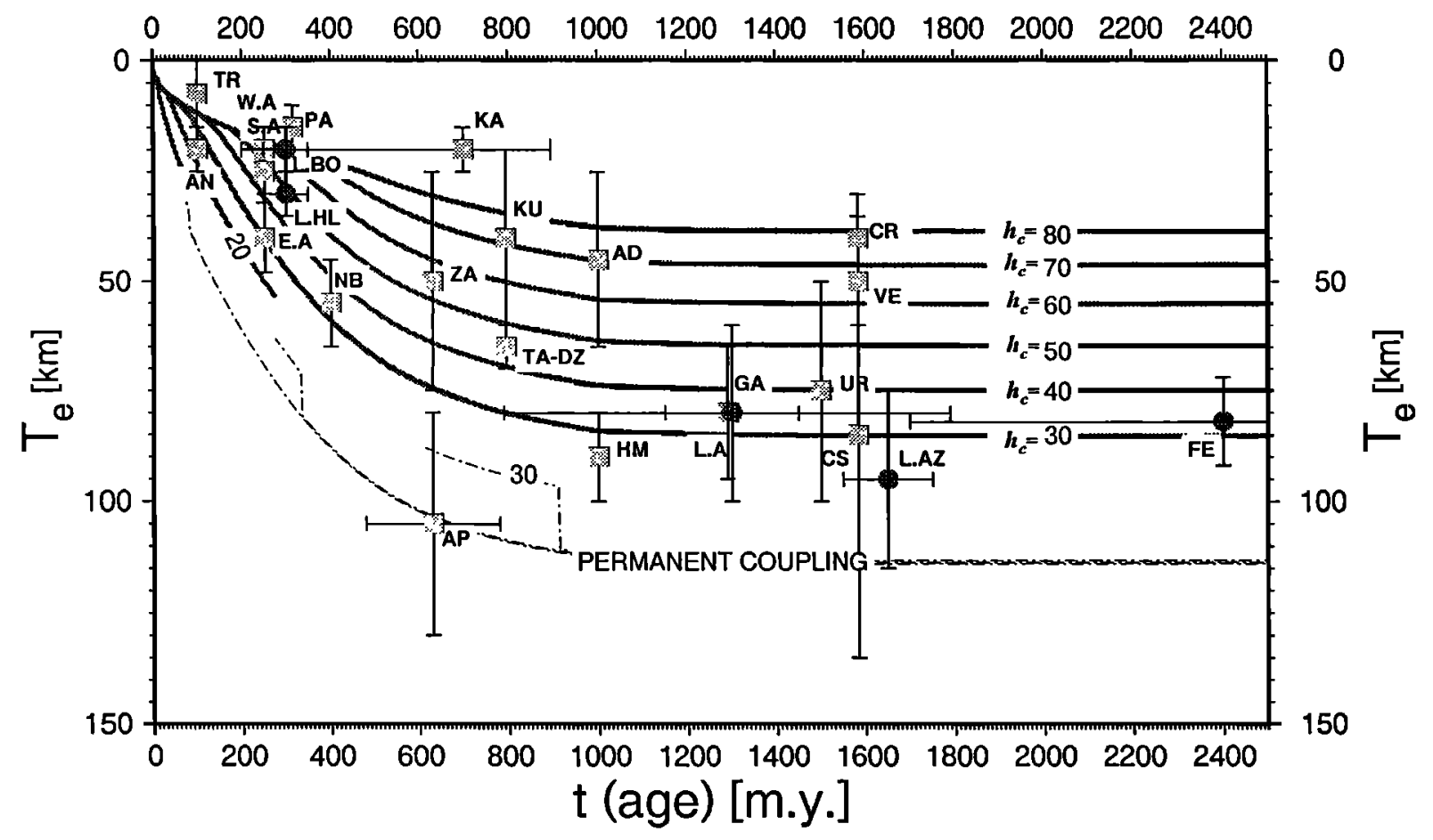

Figure 5. Predicted dependence between the thermal age and $T_{e}$ for possible values of crustal thickness $h_{c}$. Observed values of $T_{e}$ are added (See Figure 2 for references). Observed values of $h_{c}$ are also available for each estimate of $T_{e}$ shown here. For example, for the points FE, E.A., W.A., and S.A. $h_{c}$ is around $30 \mathrm{~km}$. For the points NB, TA, DZ, and UR it is between 40 and $50 \mathrm{~km}$. For the points CS and VE $h_{c}$ is $-60 \mathrm{~km}$. Values for $h_{c}$ can be found in the literature cited in the caption of Figure 2. Grey solid lines correspond to $T_{e}$ predictions for the decoupled lithosphere. The dashed line corresponds to the coupled lithosphere (no dependency of $T_{e}$ on $h_{c}$ ).

$T_{e}$ presented here, the values of $h_{c}$ obtained from seismic and gravity data are also available. Thus each $T_{e}$ data point can be matched with only one theoretical $T_{e}$ curve corresponding to the closest value of $h_{c}$. Within uncertainties, Figure 5 shows a good fit between predicted and "observed" values of $T_{e}$ (and $h_{c}$ ). For example, for Fennoscandia (FE) and Alps (E.A., W.A., S.A.) the observed values of $h_{c}$ are around $30 \mathrm{~km}$, for the North Baikal (NB), Tarim basin (TA), Dzungarian basin (DZ), Urals (UR) $h_{c}$ is between $40-50 \mathrm{~km}$ though the crustal thickness for the Caucuses (CS) is around $60 \mathrm{~km}$ [Belyayevsky, 1974]. The values of $h_{c}$ for the other data points are mostly about $40 \mathrm{~km}$. Principal disagreements between the computed and observed $T_{e}$ occur only for the regions that possibly underwent recent thermal resetting (like the Kazakh shield, KA in Figure 5, which has undergone Jurassic rejuvenation).

\section{$T_{e}$ and Regionally Distributed Surface Loads (Topography)}

The previous analogy with the laminated spring becomes insufficient when the lithosphere is loaded by significant laterally distributed loads. The differential stresses caused by such loads may lead to variation in the thickness of the mechanical layers and they will be no more equal to $h_{1}, h_{2} \ldots$ Figure 5 shows a quite satisfactory fit between the data and predictions within possible uncertainties, though in some cases (e.g., Carpathians, Pamir, Kunlun, Kazakh shield, Alps) there is a systematic $\sim 20 \%$ deviation between the predictions and observations, such that the predicted values of $T_{e}$ are generally larger than the observed ones. We have to assume that in these cases the lithospheric strength is reduced by some additional complementary mechanism. We considered possible factors that could affect the local values of $T_{e}$. The elevated surface topography creates normal stresses of about 50-150 MPa. This is enough to cause significant flexural deformations (and bending stresses) of the underlying lithosphere. The surface topography is therefore one of the best candidates for major factors controlling the effective strength of the lithosphere. To investigate this point, we computed deformations of the lithospheric plate loaded by distributed topography loads. Figure $6 \mathrm{a}$ shows an example of a large mountain belt of $3.5 \mathrm{~km}$ height and $200 \mathrm{~km}$ width overlying $\sim 250 \mathrm{Ma}$ plate with a 35-km-thick quartz-dominated crust. The elastic thickness of such a plate before loading is about $45 \mathrm{~km}$ (Figure $4 \mathrm{~b}$ ). The mountain load leads to significant spatial variations of $T_{e}$ that drops beneath the belt axis from 45 to $20 \mathrm{~km}$. As a result the mountain appears more locally compensated than the adjacent regions. $T_{e}$ variations can be traced via seismic reflection and refraction data on deflection of the Moho and via gravity anomalies associated with this deflection (Figure 6a, top). The theoretical possibility of strength reduction beneath the mountains was already demonstrated by Burov and Diament [1992] for continents and by Wessel [1993] for oceans. Before that a number of authors mentioned such effect from direct observations of flexure [LyonCaen and Molnar, 1983, 1984; Zoetemeijer et al., 1990; Abers and Lyon-Caen, 1990]. One can also see from Figure 6a that the high topography is able to create large zones of brittle failure in adjacent regions, usually associated with shallow seismicity, whereas the higher lithostatic pressure beneath the topographic feature itself confines the material, thus preventing it from brittle failure. For the same reason that causes strength reduction beneath the mountains, flat basins, cratons, and eroded areas may exhibit much higher strength than the adjacent areas of higher relief and/or intensive orogeny [e.g., Lyon-Caen and Molnar, 

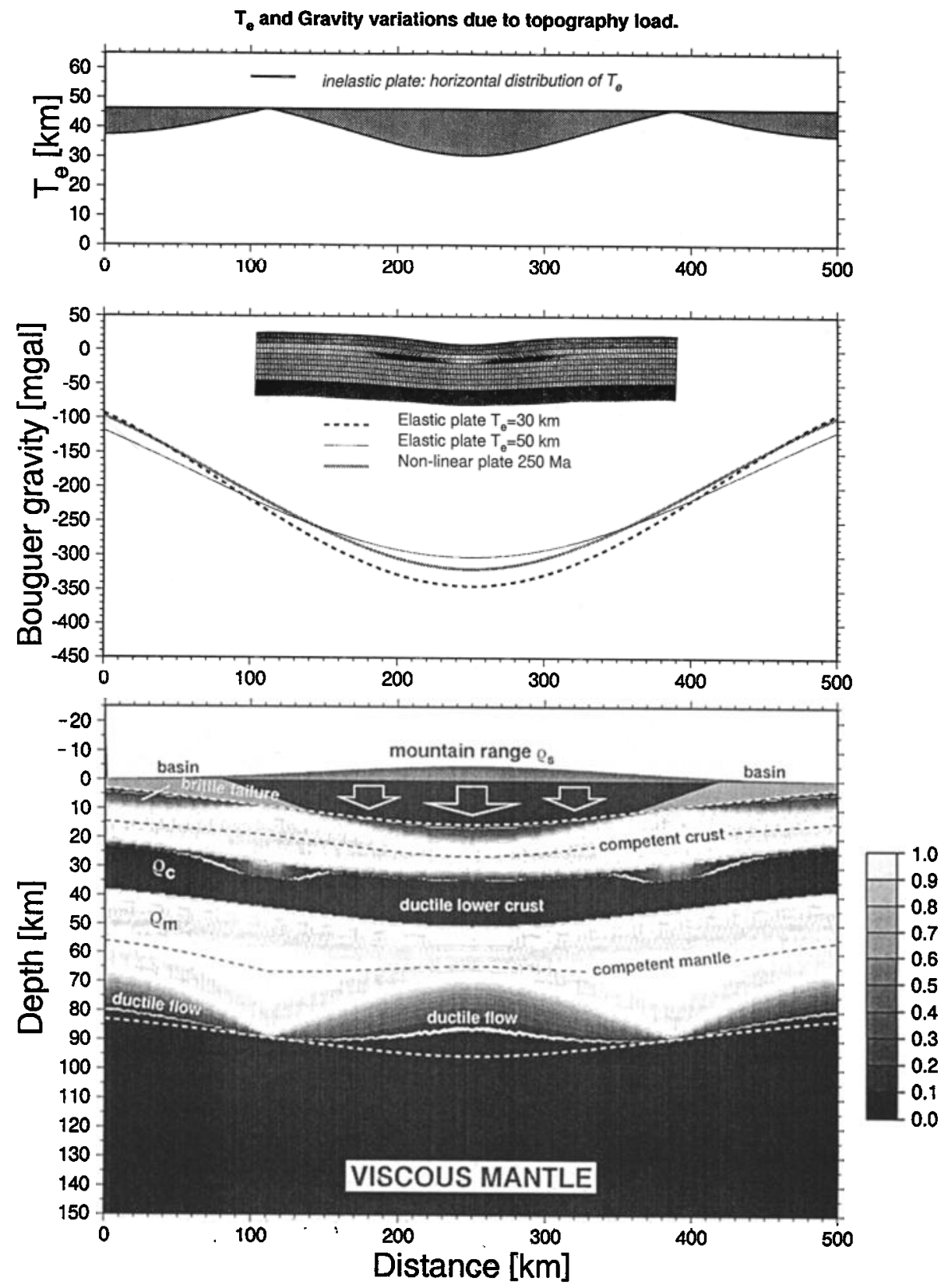

Figure 6a. Local variations of the lithospheric strength in a $250 \mathrm{Ma}$ continental plate (normal surface heat flow for all cases except Figure $6 \mathrm{~b}$ ). Crustal thickness is $35 \mathrm{~km}$. The top of the figure shows spatial variations of $T_{e}$ along the loaded inelastic lithospheric plate, compared with the initial $T_{e}$ for a nonloaded plate. Middle of the figure shows gravity effect due to depression of the Moho. Bottom of the figure shows the rheological structure and strength variations in the loaded plate (nondimensional strength is given as ratio of the actual (inelastic) deviatoric stress $\Delta \sigma_{n}$ to the elastic stress $\Delta \sigma_{e}$ that could be expected for the same strains in the case of a purely elastic rheology). This gives the ratio of the strength after loading to the strength before loading. The white areas $\left(\Delta \sigma_{n} \Delta\right.$ $\left.\sigma_{e}=0.9 \sim 1\right)$ thus correspond to effectively elastic zones. The dark areas $\left(\Delta \sigma_{n} \Delta \sigma_{e} \rightarrow 0\right)$ represent inelastic (brittle, ductile) zones. Loading a continuous plate by topography relief (mountain belt of $3.5 \mathrm{~km}$ height and $200 \mathrm{~km}$ width), $250 \mathrm{Ma}$ lithosphere. Just to compare with our semi-analytical approach, we also show in the middle of the figure the deformation of the finite element grid produced by the popular finite element code "Tecton". Note large straining in the lower crust that favours decoupling. The effect of the topography placed on a discontinuous plate is similar to the effect of the commulative boundary force and moment (Figures $6 \mathrm{c}$ and $6 \mathrm{~d}$ ).

1983, 1984; Zoetemeijer et al., 1990; Abers and Lyon-Caen, 1990]. Of course one should remember that, for example, foreland basins may show both low and high values of $T_{e}$ due to "inheritance" of weak/strong zones in the underlying lithosphere
[Cloetingh et al., 1982]. Stretched crust is weak and forelands which develop on or close to passive margins may inherit these initial low values of $T_{e}$. For example, Van der Beek and Cloetingh [1992] demonstrated that at least preceding thermo- 

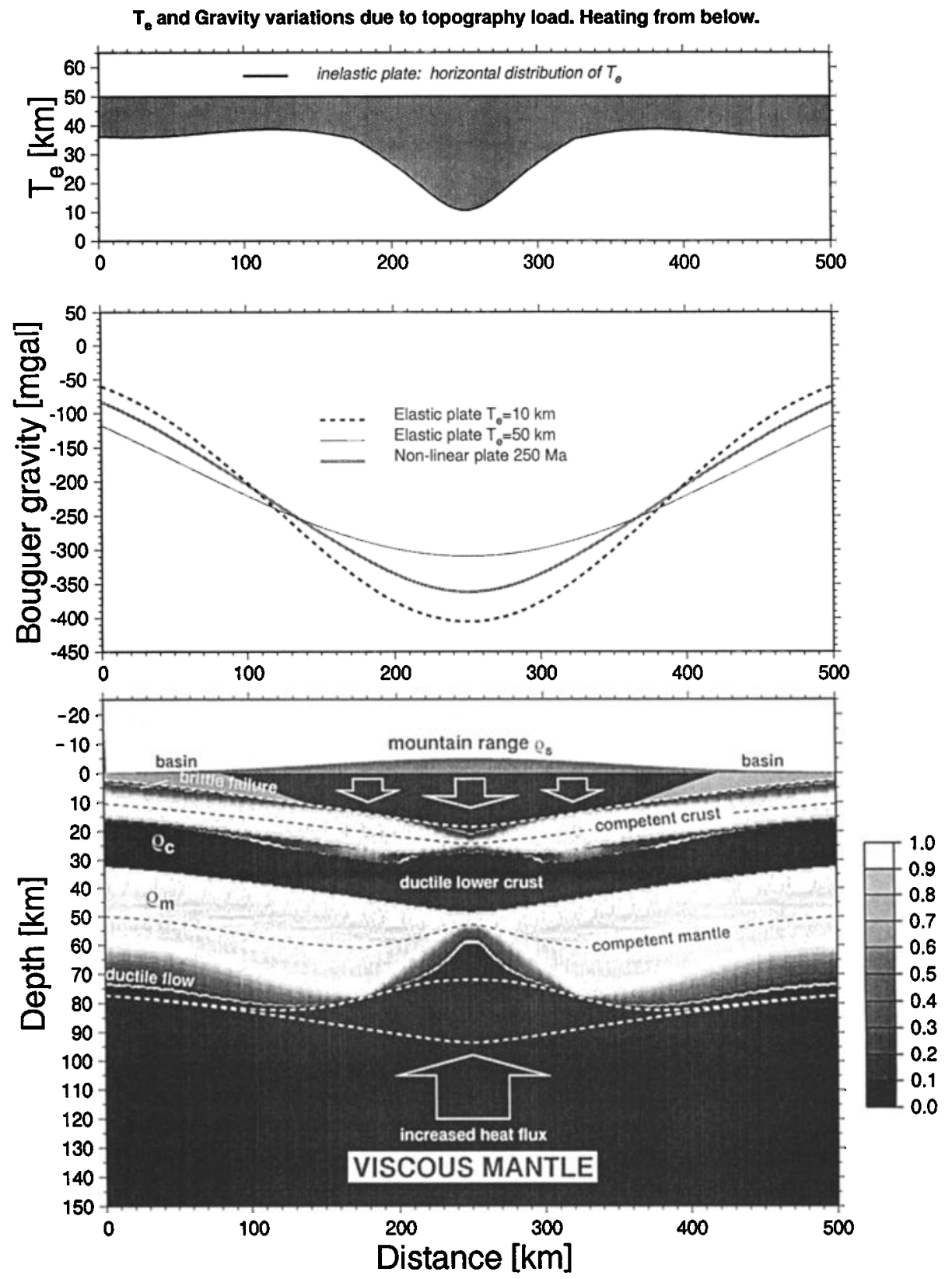

Figure 6b. Same as Figure $6 \mathrm{a}$ but with extra heating from below added. Surface heat flux $200 \mathrm{~mW} / \mathrm{m}^{2}$.

tectonic events must be considered to explain the present-day flexural response of the lithosphere in the Betic Cordilleras (Spain). After all, the regional intraplate stresses may be of importance in some cases, even if these stresses are lower than buckling/folding limits [Cloetingh et al., 1982; Cloetingh and Burov, 1994].

The idea that $T_{e}$ may be controlled by surface topography also applies to the oceans, thus allowing explanation for strength reduction reported beneath the seamounts and oceanic islands [McNutt and Menard, 1982; Calmant and Cazenave, 1986]. The general difference between the oceanic and continental lithosphere is that the first has a negligibly thin crust and low thermal thickness (see appendix). For example, one can predict more than $50-80 \%$ strength variations beneath the Hawaiian Archipelago (around $5 \mathrm{~km}$ high from sea bottom, more than 100 $\mathrm{km}$ width) just due to the load of the archipelago itself.
Additional thermal heating from below in combination with the mountain load can dramatically reduce the effective strength of the lithosphere (Figure $6 \mathrm{~b}$ ). Figures $6 \mathrm{a}$ and $6 \mathrm{~b}$ show strength variations due to topography load placed on a continuous plate. The strength variations due to topographic loads located in the vicinity of plate edge (broken plate, for example, subduction zones) is similar to the effect of the boundary forces shown in Figure $6 \mathrm{c}$ and discussed below.

The results of time-dependent finite element computations that we made additionally to the above experiments, also confirm that loading by topography leads to maximum inelastic straining in the weak lower crust, resulting in a flow of the low-viscosity material through the lower crustal channel (Figure 6a, middle). Even if the upper crust and mantle lithosphere are mechanically coupled before loading, after some time they may become decoupled by this flow. Moreover our experiments showed that 

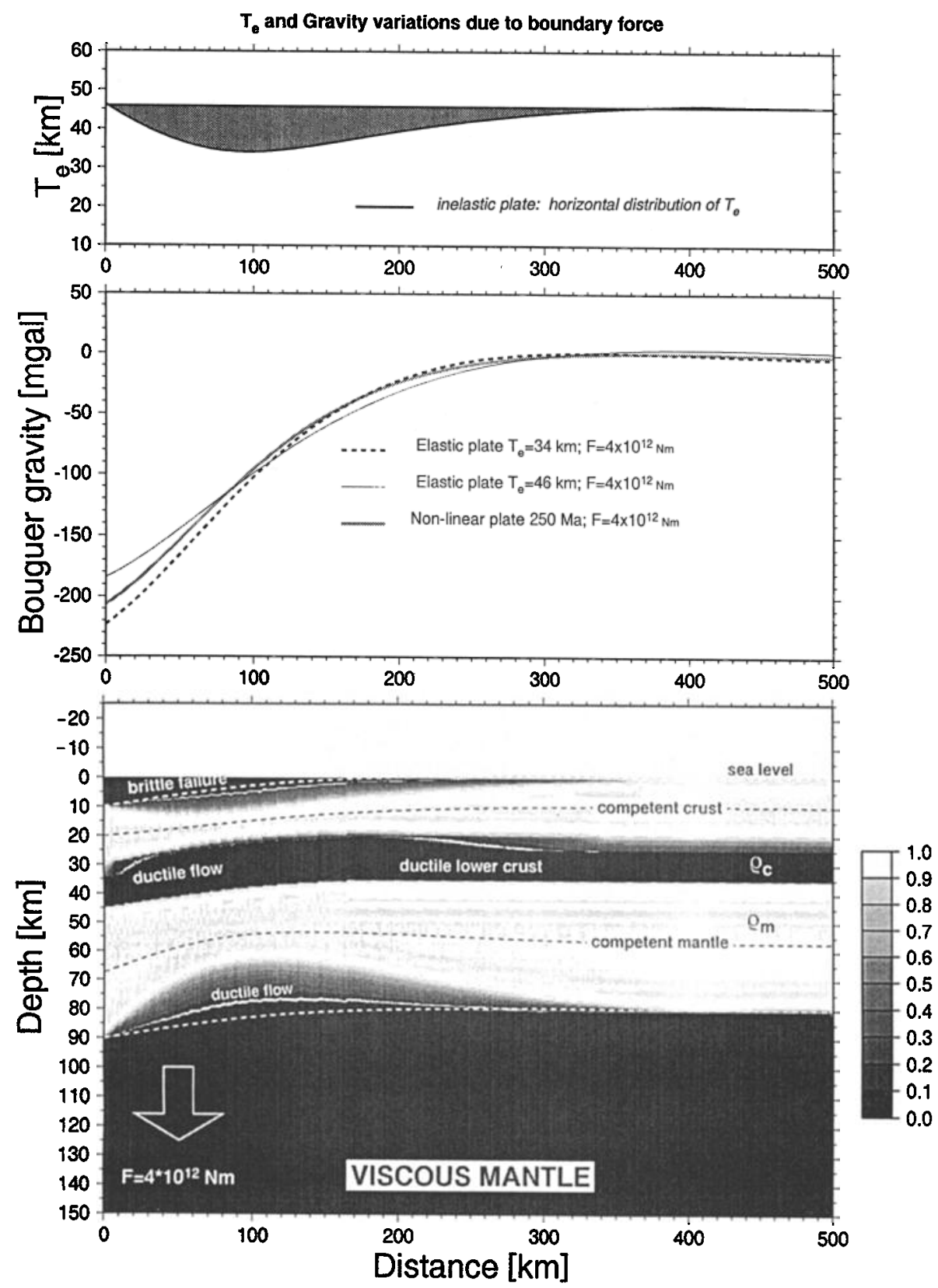

Figure 6c. Plate boundary force $\left(\left.F_{x}\right|_{x=0}\right.$ ) (associated with edge loads, for example, with total mass anomalies represented by the slabs). The effect of boundary force is also similar to the effect of the topography load placed nearby the plate boundary (e.g., in subduction zones).

in certain cases (very low effective viscosity of the lower crust) the flow in the lower crust may be so intensive that the compensation of the topographic load will be limited to the lower crust, and the flexural response of the mantle lithosphere will be attenuated. However, such low viscosities $\left(1 \times 10^{18}-1 \times 10^{19} \mathrm{~Pa} \mathrm{~s}\right)$ would generally require a quite "hot" crustal geotherm (young or thermally reset (volcanic, rift) areas.)

\section{$T_{e}$ and Plate-Boundary Conditions: End Forces and Bending Moments}

In zones of continental collision, the lithosphere is subjected to significant plate-boundary loads, partly from the overridden part of the plate, interaction with another plate, and with down- going convective flows beneath the lithosphere. The typical effective weight anomalies represented by slabs are about $10^{12}$. $10^{13} \mathrm{~N} / \mathrm{m}$, whereas the effective plate-boundary bending moments are of order $10^{16}-10^{17} \mathrm{Nm} / \mathrm{m}$ [e.g., Lyon-Caen and Molnar, 1983; Sheffels and McNutt, 1986; Burov et al., 1990; Royden, 1993; Kruse and Royden, 1994]. Such plate-boundary loads create significant local strength variations in the bending lithosphere (Figure 6c). For example, a boundary force of $F=4 \times$ $10^{12} \mathrm{Nm}$ leads to $20-30 \% T_{e}$ reduction in area $100-200 \mathrm{~km}$ from the edge of the plate, with a maximum reduction in the vicinity of the peripheral bulge (Figure $6 \mathrm{c}$ ). The bending boundary moment has a similar effect, but with the maximum reduction in $T_{e}$ near the edge of the plate (Figure $6 \mathrm{~d}$ ). As stated previously, this result also applies to the oceanic lithosphere, allowing to explain $T_{e}$ variations reported in fracture zones and deep-sea trenches 

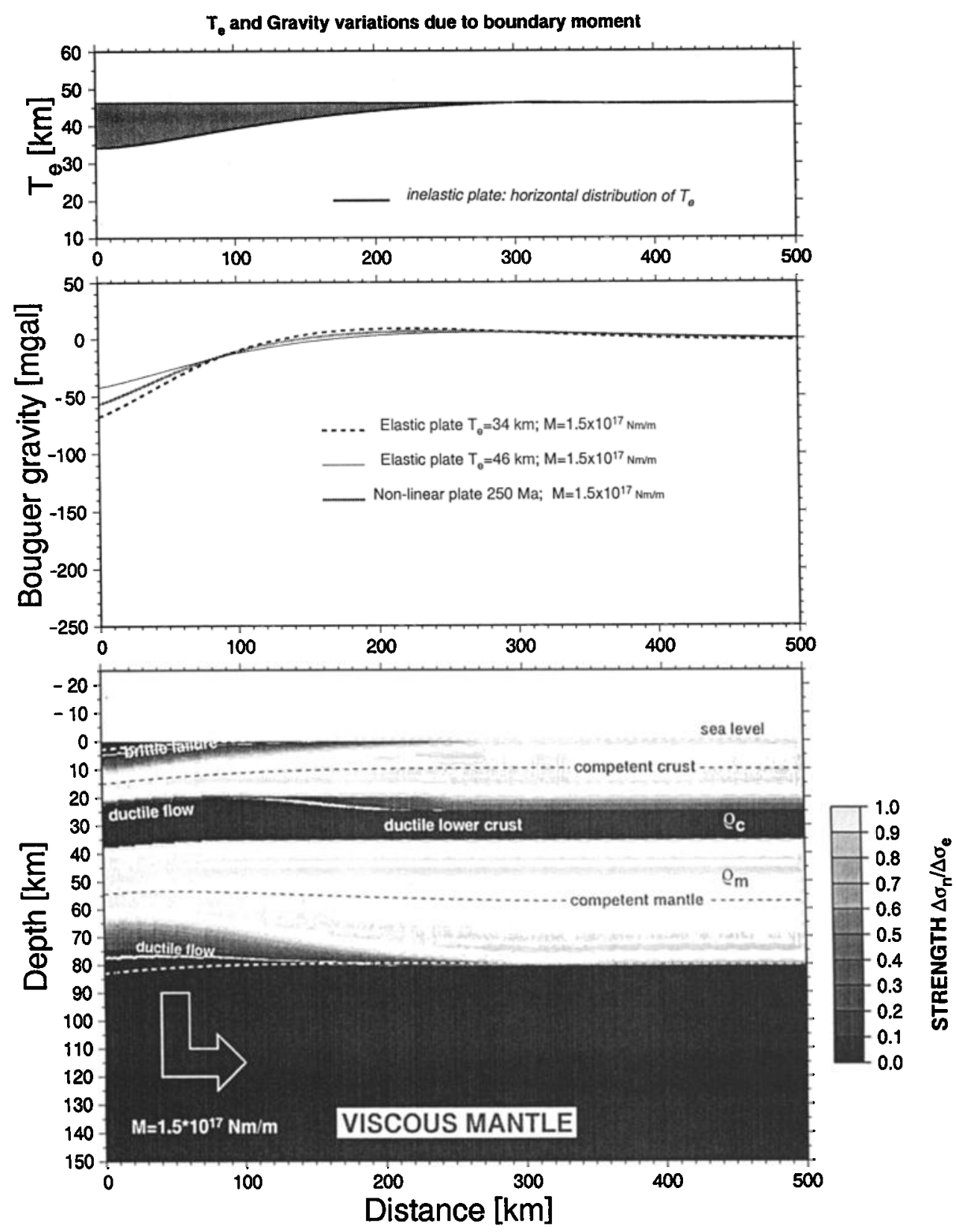

Figure 6d. Plate boundary moment $\left(\left.M_{x}\right|_{x=0}\right)$ represents the commulative effect of the interaction with another plate and of distributed loads acting on the plate from above and below (e.g., due to downgoing convective flow).

[McNutt and Menard, 1982; Wessel and Haxby, 1990; Judge and $M c N u t t, 1991]$. One should also note that the regional intraplane horizontal stresses may affect the position of the internal rheological zones (Figure 3d). This can be especially important in the zones of rifting where the extensional stresses may reach hundreds of megapascals [e.g., Chéry et al., 1992].

\section{$T_{e}$ and Dynamic Variation of Vertical Load (Subsidence Due to Sedimentation and Unloading Due to Erosion and Other Surface Processes)}

It follows from our results that the variation of surface load in time, for example, due to sedimentation processes in sedimentary basins, or erosion in high relief areas, can dynamically change the strength of the underlying plate. Particularly, this should be important for the problems of back-stripping. As it is commonly accepted [Watts and Torne, 1992] the main factors responsible for the subsidence of extensional basins are the crustal thinning at the time of rifting, cooling, and subsequent sedimentary loading. Various mechanisms have been proposed to explain the origin of thinning, but most of them relate crustal thinning to the pure horizontal extension caused by different processes such as plastic necking, mantle extension or horizontal creep flow in lower crust [Bott, 1971; White and McKenzie, 1988]. All these models separate mechanisms of crustal thinning and sedimentation. However, we can show that sedimentation and crustal thinning are interdependent, because the increase of the vertical load due to deposition of sediments results in weakening of the underlying crust. Particularly, this may change the amplitude (or rate) of subsidence by $10-20 \%$. Of course the main mechanism of crustal thinning (horizontal extension) retains its leading role, 
but the additional strength decrease due to the vertical loading can be also important. It may even facilitate the process of extension in the cases when extension did not stop after the first rifting stage.

In most cases the reconstruction of basement geometry and evaluation of the amount of crustal thinning is done by removing sediments without taking into account $T_{e}$-load dependency, that is, using the present-day $T_{e}$ estimates or simply zero $T_{e}$ to model lithospheric flexure at the initial time when there were no sediments at all (backstripping [e.g., Watts and Torne, 1992]). Variation of surface load with time during the processes of sediment deposition in sedimentary basins and erosion in the uplifted flank areas dynamically changes the strength of the underlying lithosphere. For passive margins this issue was discussed in early work by Cloetingh et al. [1982]. We confirm that especially for the young lithosphere, $T_{e}$ variations due to sediment deposition may be about $20 \%$. This can lead to $10 \%$ difference in the basement geometry and rate of subsidence predicted by the traditional linear models. This suggests that the results of back-stripping reconstructions based on the assumption of a zero, or nonzero constant, or only an age/temperature dependent $T_{e}$, may require some reconsideration. The same applies to postglacial rebound studies. The effective strength of the lithosphere varies during postglacial rebound and therefore affects the estimates of the effective viscosity of the underlying mantle.

\section{$T_{e}$ and Plate Curvature}

A parameter characterizing the degree of flexural deformation is the local radius of the plate curvature $\left(R_{x y}\right)$. It can be obtained from geometry of plate deflection (basement or Moho) known from geodetic, seismic, and gravity data. On the other hand, the radius of plate curvature is related to the gradient of bending stresses within the plate $\gamma: R_{x y} \approx-\left(w^{\prime \prime}\right)^{-1} \sim-\left(\gamma\left(1-v^{2}\right) / E\right)^{-1}$. Therefore the dependence between the local deformation of the lithosphere and its strength can be described as a dependence between $T_{e}$ and $R_{x y}$. We calculated $T_{e}-R_{x y}$-age relationships both for coupled and decoupled rheology and compared it with available data on $T_{e}$ and $R_{x y}$ (Figure 7). Unfortunately, most of present publications on lithospheric flexure do not provide estimates for $R_{x y}$, but there are data on the correlation between the dip angle $\alpha, T_{e}$, and radius of arc front curvature $R_{x z}$ [Turcotte and Schubert, 1982; McNutt et al., 1988; Ramalli, 1994]. The dip angle $\alpha \approx-\left.w^{\prime}\right|_{x=x}$ is related to $R_{x y} \approx-\left(w^{\prime \prime}\right)^{-1}$. According to the theory of plates and shells, the radius of the plate/shell curvature in any direction is linearly proportional to the ratio of the elastic thickness to the bending moment. Therefore if $T_{e}$ decreases, $R_{x z}$ should decrease in the same way as $R_{x y}$. Though $R_{x z}$ will be greater than $R_{x y}$ if $M_{x}$ is greater than $M_{z}$. It follows that the values of $R_{x z}$ (solid squares in Figure 7) can be used as an upper bound on the values of the radius of the predominant flexure $R_{x y}$. We

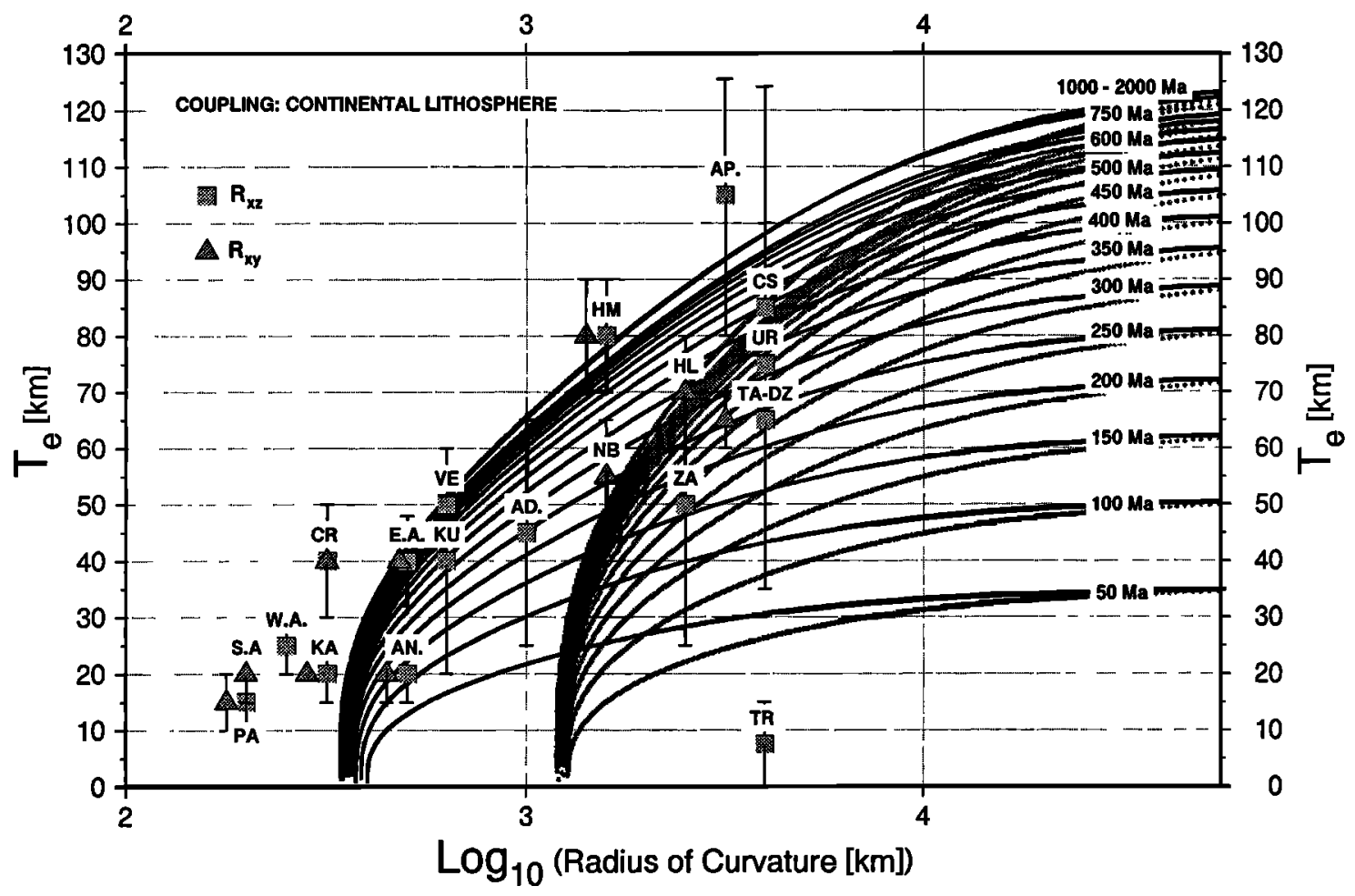

Figure 7a. Predicted dependence of the effective "momentary" elastic thickness on the age and radius of plate curvature $R_{x y}$. Data on $T_{e}-R_{x y}$ are added (see Figures 2 and 5 for notations). Dark lines correspond to the concave upward flexure, with extension in the uppermost crust and mantle (e.g., subducting plate, Figures $6 \mathrm{c}$ and $6 \mathrm{~d}$; see also Figure 3b). Grey lines correspond to the concave downward flexure, with compression in the uppermost crust and mantle (e.g. abducting/overriding plate or the case like in Figures $6 \mathrm{a}$ and $6 \mathrm{~b}$; see also Figure $3 \mathrm{~b}$ ). Solid squares correspond to estimates of arc front curvature ( $x z$ plane); triangles correspond to those in $x y$ plane. Note that the overriding (downward flexed) plate generally cannot be so highly flexed as the subducting plate, because the stresses required for the concave downward flexure are much higher than that for the concave upward flexure (the brittle areas are stronger for compression than for tension (Figure 3). Here an average value of crustal thickness $\tilde{h}_{c}=35 \mathrm{~km}$ is assumed. For other values of $\tilde{h}_{c}$, predicted $T_{e}$ should be corrected, roughly accordingly to equation (14). This figure also allows us to estimate the thermal age of the lithosphere (if $T_{e}$ and $R_{x y}$ are known). Permanently coupled lithosphere (lower crust with high temperature of creep activation, and/or very old plates). 


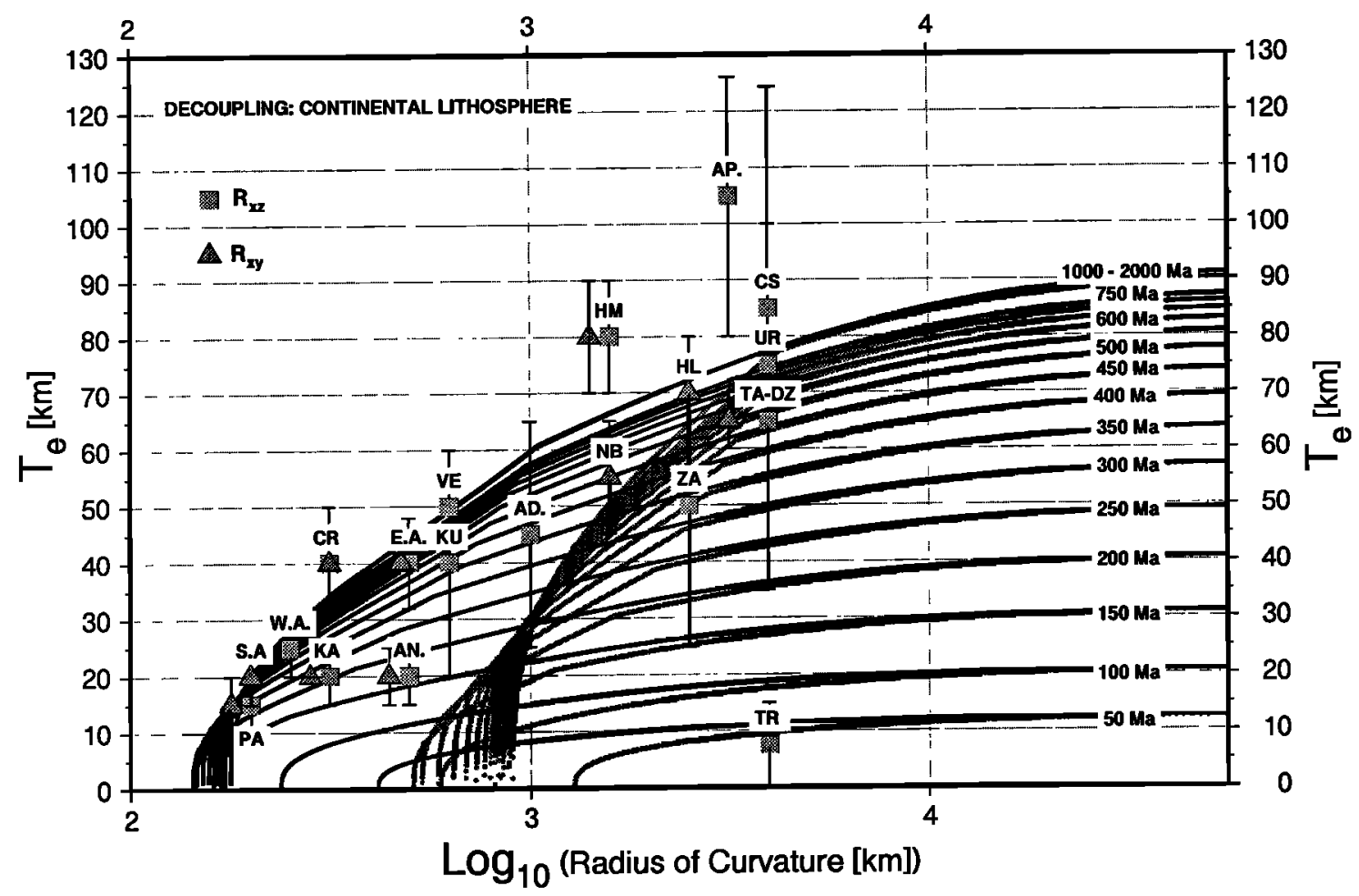

Figure 7b. Decoupled lithosphere (lower crust with low temperature of creep activation and/or young plates). The decoupled model fits most of the continental data except few cases where the lithosphere is likely to be coupled (Himalaya, Appalachians). The lithospheric flexure can dramatically decrease (by a factor of 3 or even 5 , e.g., Pamir) the effective elastic thickness of the lithosphere. The coupled rheology (Figure 7a) cannot explain low $T_{e}$ values for young lithosphere, as well as it provides worse fit to most middle-aged plates. One can also see that due to decoupling for equal ages the oceanic lithosphere may be even stronger than the continental lithosphere. The data sources on $R_{x z}, R_{x y}$ for the continental lithosphere are $R_{x z}$ (solid squares) McNutt et al. [1988]; The values of $R_{x y}$ (solid triangles) are deduced from the geometries of plate deflection from Royden [1993], Burov et al. [1990], Burov and Diament [1992], Burov et al. [1994], Kruse and Royden [1994].

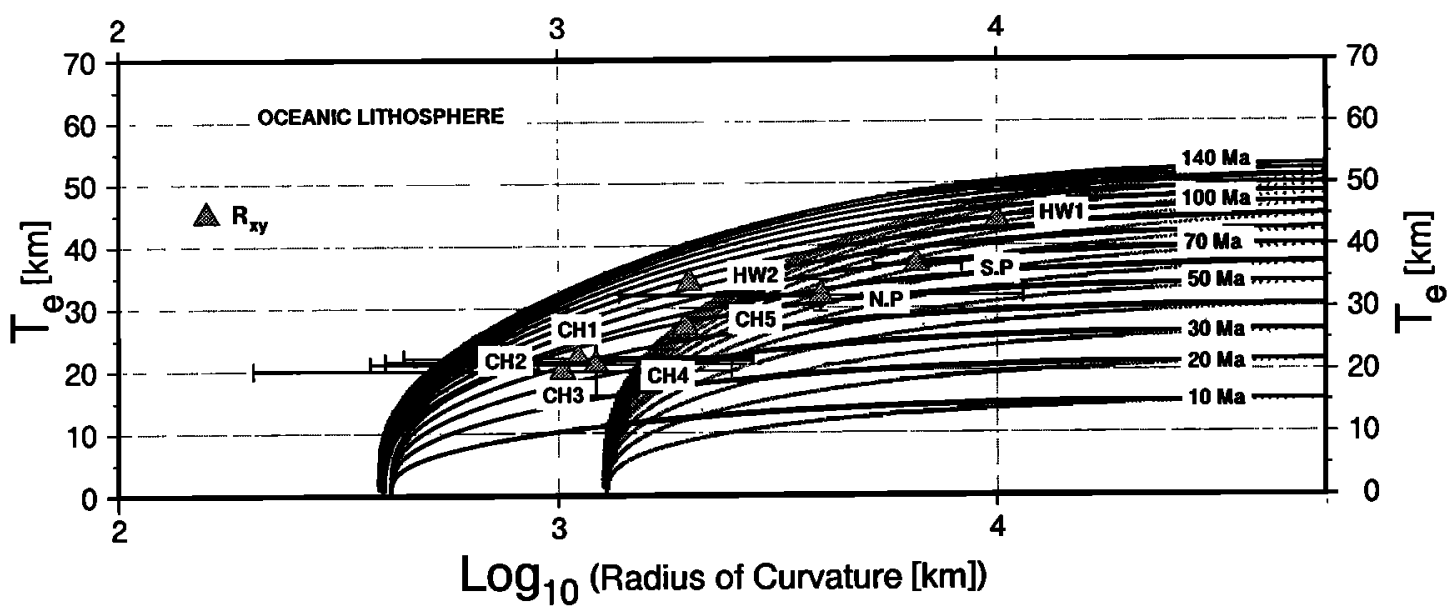

Figure 7c. Predicted $T_{e}-R_{x y}$ dependence for the oceanic lithosphere. Data for the Nazca plate [Judge and McNutt, 1991] and Hawaiian Islands [Wessel, 1993] are added. NP, North Peru; SP, South Peru; CH, Chile; H1, Hawaii surrounding; $\mathrm{H} 2$, Hawaii center.

made some estimates for $R_{x y}$ as well (solid triangles in Figure 7), having deduced them from geometries of plate deflection published by Royden [1993], Kruse and Royden [1994], and from our previous studies [Burov et al., 1990; Burov and Diament, 1992;
Burov et al., 1994]. From comparison of these estimates with data on $R_{x z}$ one can conclude that the assumption $R_{x z} \geq R_{x y}$ is valid for most continental collision belts. Results shown in Figure 7 indicate that the lithospheric flexure may be responsible 
for localized reductions of the effective elastic thickness that may be between 0.1 and 0.5 orders. For example, $T_{e}$ of the Pamir block $\left(h_{c} \sim 50 \mathrm{~km}\right)$ is obviously reduced by flexural deformations from the maximum possible $50 \mathrm{~km}$ (Figure 5 ) to $10 \mathrm{~km}$ (Figures $7 \mathrm{a}$ and $7 \mathrm{~b}$ ). It is also evident from comparison with the observations that the implication of the decoupled rheology (Figure $7 \mathrm{~b}$ ) definitely provides a much better fit to the data than does the coupled rheology (Figure 7a), except for some old and cold plates (Appalachians, Himalayas) that certainly are better explained by the coupled rheology. This leads us to the basic conclusion that most continental lithospheric plates can be characterized by a low-temperature activation (e.g., quartz-dominated or highly wet, etc.) crustal rheology.

Figure 7c shows a test of our model for the oceanic lithosphere against the data on the Nazca [Judge and McNutt, 1991] and Hawaiian Islands [Wessel, 1993]. One can see a good fit between their estimates of $T_{e}$ and our predictions: high curvature of the 30 to $45-\mathrm{Ma}$-old Nazca plate offshore Chile $\left(R_{x y} \sim 1000 \mathrm{~km}\right)$ leads to almost $30 \%-40 \%$ reduction in $T_{e}$ as compared to the same plate offshore Peru, where the radius of the plate curvature is much higher $\left(R_{x y}>5000 \mathrm{~km}\right)$. The other purpose of modeling the oceanic lithosphere was to emphasize the importance of the crust-mantle decoupling in the continents. The comparison with Figure $7 \mathrm{~b}$ shows that for equal thermal ages the oceanic lithosphere may be even stronger than the continental lithosphere, although the base of mechanical lithosphere in the oceans is much shallower than in the continents (Figures 1 and 2).

\section{Conclusion}

We propose a model that provides a rheology consistent explanation for the behavior of $T_{e}$ in continents and oceans: the strength $\left(T_{e}\right)$ of the continental lithosphere is controlled by its thermal structure as in the case of the oceanic lithosphere, but in conjunction with two other equally important complementary mechanisms: (1) the strength reduction by crust-mantle decoupling and (2) by the bending stresses that result from flexure caused by the presence of the surface and subsurface loads. These bending stresses are directly related to the plate curvature. Testing the above assumption against available data suggests that decoupling is responsible for a total reduction of $T_{e}$ by $50-90 \%$ in most places except some for very old lithosphere $(t>750-1000$ Ma). This suggests that almost everywhere in continents the crust is dominated by low-temperature activation minerals (quartz or highly wet, etc.), thus allowing use of $T_{e}$ estimates as distinct controls on the crustal rheology. For very young lithosphere it is quite possible that the lower crust can be detached from the mantle even if it has a high temperature of activation (diabase, Figure 3a). Anyway, the mantle does not contribute significantly to the total strength of very young lithosphere, and $T_{e}$ rather coincides with the depth to the base of the mechanical crust.

There is a critical value of the crustal thickness that controls the possibility of crust-mantle decoupling. This value is about $35-40 \mathrm{~km}$ for old lithospheric plates $(t>750 \mathrm{Ma})$, whereas for younger lithosphere it is essentially age-dependent. Coincidentally, this critical value for old lithosphere is equal to the average, or most typical thickness of the continental crust. This result probably explains the bimodality in the continental $T_{e}$ distribution noted by Watts [1992]. In order to understand the meaning of $T_{e}$ one has to consider crustal thickness, in addition to the traditional parameters such as age/geotherm.

Reduction of $T_{e}$ by nonlinear flexure is a third important mechanism that may lead to localized reductions in the lithospheric strength of up to a factor of 5. Most of available $T_{e}$ estimates were obtained in regions of intensive plate deformations $\left(R_{x y} \leq 10^{3} \mathrm{~km}\right)$. Therefore they cannot be simply extended to the nondeformed parts of the plates, because strong localized deformation in the deformed areas where these estimates were obtained can reduce $T_{e}$ by a factor of $2-5$, whilst the rest of the plate maintains the initial higher strength (Figures $7 \mathrm{~b}$ and $7 \mathrm{c}$ ). Cochran [1980] suggested a similar idea on the basis of observations. Strong variation of $T_{e}$ in Alps and Apennines also can be explained on the same basis [Royden, 1993; Kruse and Royden, 1994; Okaya et al., 1994]. The flexure of the lithosphere is, of course, not the only mechanism responsible for significant deviatoric stresses, but at least one of the most evident. In zones of active rifting or compression, the lithospheric strength is additionally reduced by high regional horizontal stresses, by local thermal anomalies, and by possible preexisting mechanical heterogeneities [e.g., Chéry et al., 1991]. For example, in most elastic plate models, horizontal tectonic force is ignored because it does not affect the deflections of the elastic plate until the plate starts to buckle. In the inelastic plate the horizontal force may decrease the value of $T_{e}$ and shift positions of the neutral planes and of the rheological interfaces (Figure 3c).

As long as orogeny continues, the strength $\left(T_{e}\right)$ of the lithosphere underlying the orogenic belt decreases. Plate unloading due to erosion, for example, will then result in an increase of the lithospheric strength. This also concerns the other processes associated with modification of surface topography and loads, like sedimentation (decrease of $T_{e}$ ), postglacial rebound, and erosion (increase of $T_{e}$ ). Therefore $T_{e}$ reflects a current dynamic balance between the topography, plate-boundary forces, and lithospheric structure. $T_{e}$ dynamically varies to adopt changes in the surface and subsurface loads. This result implies a possible need to reconsider previous results of modeling of processes associated with dynamic changes of the surface loads, like the above mentioned postglacial rebound and basin subsidence. For example, the active dynamic role of the lithosphere in surface load-mantle balance during postglacial rebound may significantly change the estimates of the effective viscosity of the mantle.

The existing $T_{e}$ estimates, in combination with the proposed approach, provide additional independent constraint on the plate history, its thermal state and rheological composition. Particularly, strong separation between $T_{e}$ values for coupled lithosphere and those for decoupled lithosphere allow us to use $T_{e}$ as a discriminating parameter on the crustal rheology. Finally, from comparison of the observed $T_{e}$ with values, predicted by our model, one can assess whether the examined area underwent thermal resetting or other significant tectonic events, as well as discriminate between different possible crustal compositions.

\section{Appendix: Thermal Model of the Continental Lithosphere}

We estimate the thermal structure of the lithosphere $(T=T(y, x, t))$ using a half-space cooling model incorporating radiogenic heat generation in the crust and viscous friction heating at the crust-mantle boundary. The equations of thermoconductivity for this model are

$$
\begin{aligned}
& \frac{\partial T}{\partial t}-\chi_{c 1} \Delta T=\left[\chi_{c 1} \rho_{c} H_{s} \exp \left(\frac{-y}{h_{r}}\right)\right] / k_{c 1} \quad\left(0 \leq y \leq h_{1}\right) \\
& \frac{\partial T}{\partial t}+u_{c 2}(y) \frac{\partial T}{\partial x}+v_{c 2}(y) \frac{\partial T}{\partial y}-\chi_{c 2} \Delta T= \\
& \frac{\chi_{c 2}}{k_{c 2}}\left[\mu_{c 2}\left(4\left(\frac{\partial^{2} \Psi}{\partial x \partial y}\right)^{2}+\left(\frac{\partial^{2} \psi}{\partial y^{2}}-\frac{\partial^{2} \psi}{\partial x^{2}}\right)^{2}\right)+\rho_{c} H_{s} \exp \left(\frac{-y}{h_{r}}\right)\right]
\end{aligned}
$$




$$
\begin{array}{r}
\left(h_{1}<y<h_{c}\right) \\
\left(h_{c}<y \leq a\right)
\end{array}
$$$$
\frac{\partial T}{\partial t}+u_{m 0} \frac{\partial T}{\partial x}-\chi_{m} \Delta T=0
$$$$
\text { where } \Delta T=\left(\frac{\partial^{2} T}{\partial x^{2}}+\frac{\partial^{2} T}{\partial y^{2}}\right) \text {. }
$$

The boundary and initial conditions are: $T(0, t)=0^{\circ} \mathrm{C}$ (temperature at the upper surface $=$ const at time $t(t$ is the thermal age) $) ;(a, t)=T_{m}=1350^{\circ} \mathrm{C}(a \approx 250 \mathrm{~km}$ is the depth to the thermal bottom, or thermal thickness ); $T(y, 0)=T_{m}$ (homogeneous temperature distribution at the beginning).

The values of the parameters of the thermoconductivity equations used here are $\rho_{c}=2650 \mathrm{~kg} \mathrm{~m}^{-3}, \rho_{c 2}=2900 \mathrm{~kg} \mathrm{~m}^{-3} ; k_{c}=2.5$ $\mathrm{Wm}^{-1}{ }^{\circ} \mathrm{K}^{-1} ; k_{c 2}=2 \mathrm{Wm}^{-10} \mathrm{~K}^{-1} ; k_{m}=3.5 \mathrm{Wm}^{-10} \mathrm{~K}^{-1} ; \quad \chi_{c}=8.3 \times 10^{-7}$ $\mathrm{m}^{2} \mathrm{~s}^{-1} ; \chi_{c 2}=6.7 \times 10^{-7} \mathrm{~m}^{2} \mathrm{~s}^{-1} ; \chi_{m}=8.75 \times 10^{-7} \mathrm{~m}^{2} \mathrm{~s}^{-1} ; H_{s}=7.5-9.5 \times 10^{-10}$ $\mathrm{W} \mathrm{kg}{ }^{-1} ; H_{c 2} C_{c 2}^{-1}=1.7 \times 10^{-13}{ }^{\circ} \mathrm{K} \mathrm{s}^{-1}$. Here $\chi_{c 1}, \chi_{c 2}, \chi_{m}$ are coefficients of the thermal diffusitivity, and $k_{c l}, k_{c 2}$ and $k_{m}$ are respective coefficients of the thermal conductivity of the upper, lower crust and mantle; $t$ is time; $\rho_{c}, \rho_{c 2}$ is the density of the upper and lower crust, respectively, $H_{s}$ is the surface radiogenic heat production rate per unit mass, and $h_{r} \approx 10 \mathrm{~km}$ is the depth scale for the decrease in radiogenic heat production. The term $\chi_{c 2} k_{c 2}{ }^{-1} \mu_{c 2}\left(4\left(\psi_{x y}^{\prime \prime}\right)^{2}+\left(\psi_{y y}^{\prime \prime}-\Psi_{x x}^{\prime \prime}\right)^{2}\right) \approx$

$\chi_{c 2}\left(2 k_{c 2}\right)^{-1} \sigma_{c 2}^{d} \partial u_{c 2}(y) / \partial y \approx \chi_{c 2} k_{c 2} \tilde{\mu}_{c 2} u_{c 20}{ }^{2} /\left(h_{c}-h_{1}\right)^{2} \quad$ accounts for the dissipative heat generation due to possible viscous sliding between the crustal and mantle portions of the lithosphere: $u_{c 2}=\partial \psi / \partial y$ is the horizontal velocity of the differential movement in the lower crust, $v_{c 2}=-\partial \psi / \partial x$ is the vertical velocity; $\sigma_{c 2}^{d}$ is the shear stress and $\partial u_{c 2}(y) / \partial y=\dot{\varepsilon}_{c 20}$ is a component of shear strain rate due to the differential movement $\left(\dot{\varepsilon}_{11}=2 \partial u / \partial x ; \dot{\varepsilon}_{12}=\partial u / \partial y+\partial v / \partial x ; \dot{\varepsilon}_{22}=2 \partial v / \partial y\right) ; \tilde{\mu}_{c 2}$ is the effective mean viscosity of crustal material in the low crustal viscous channel; $u_{c 20}$ is the mean velocity of the differential motion between the upper crust and the upper mantle. $\sigma_{c 2}^{d}$ and $\tilde{\mu}_{2}$ are obtained from the constitutive relation (1b) assuming $\mu_{e f f}=\sigma_{c 2}^{d} / 2 \dot{\varepsilon}_{c 20}$. The term $H_{c 20} C_{c 20}^{-1}$ accounts for radiogenic heat in the lower crust where $H_{c 20}$ is average radiogenic heat production rate per unit mass in the lower crust and $C_{c 20}$ is the specific heat capacity. The solution of the system (Al) is obtained with the assumption of heat flux continuity across the upper and lower crust and mantle lithosphere:

$$
\left.\left.T\right|_{h_{1}-0} ^{=} T\right|_{h_{1}+0} ;\left.\left.\frac{\partial T}{\partial y}\right|_{h_{1}-0} ^{=} \frac{\partial T}{\partial y}\right|_{h_{1}+0} ;\left.T\right|_{h-0}=\left.T\right|_{h+0} ;\left.\frac{\partial T}{\partial y}\right|_{h-0}=\left.\frac{\partial T}{\partial y}\right|_{h_{1}+0}
$$

Applying the solution $T(x, y, t)$ to the constitutive equations (1), we calculate the YSEs shown in Figure 3. Some workers prefer to use a steady state heat conduction equation $(\partial T / \partial t=0$;

$\left.\partial T /\left.\partial y\right|_{(0, t)}=-k_{c} q_{s}\right)$. This allows them to estimate temperature by direct integration of the surface heat flux only. However, this approach may not be accurate enough for the areas characterized by large amount of sediments or by low surface heat flow $(q<40$ $\mathrm{mW} \mathrm{\textrm {m } ^ { - 2 }}$, low signal-to-noise ratio.)

Acknowledgments. A. Watts significantly contributed to and inspired this study. We considered him as a third author of this paper but unfortunately could not overcome his personal insistence that his participation was not enough to constitute an authorship. E. B. Burov is thankful to S. Cloetingh, M. McNutt, M. G. Kogan, A. Poliakov, Y. Podladchikóv, L. Lobkovsky, C. Ruppel for numerous discussions. We are especially indebted to $P$. Molnar for his rigorous review of the paper, suggestions and long discussions which all significantly improved the manuscript. Comments by F. Stacey were very useful. H.-J. Zeyen made a lot of useful comments on the manuscript. J.-C. Komorovsky greatly improved the English usage of the final text. The public domain graphics package GMT by $P$. Wessel and $H$. P. Smith was used to prepare figures of this paper. The finite element code "Tecton" kindly provided by J. Melosh was used to test some of the numerical results. E. B. Burov benefited from a postdoctoral grant of Ministère de la Recherche (France). IPGP contribution 1342.

\section{References}

Abers, A.G., and H. Lyon-Caen, Regional gravity anomalies, depth of the foreland basin and isostatic compensation of the New Guinea highlands, Tectonics, 9, 1479-1493, 1990.

Achache, J., M. Hamoudi, and Y. Cohen, Constraints on seismic tomographic models of the continental lithosphere from Magsatbased magnetization models (abstract), Eos Trans. AGU 75(44) Fall Meeting suppl., 620, 1994.

Alexandrov, A.V., and V.D. Potapov, Basics of Theory of Elasticity and Plasticity (in Russian), 400 pp., Vischaya Schkola, Moscow, 1990.

Banda, E., and S. Cloetingh, Physical properties of the Europe's lithosphere, pp. 71-80, edited by D. Blundell, R. Freeman, and $S$. Mueller, A Continent Revealed: the European Geotraverse, Cambridge University Press/European Science Foundation, New York, 1992.

Bechtel, D., D.W. Forsyth, V.L. Sharpton, and R.A.F. Grieve, Variations in effective elastic thickness of the North American lithosphere, Nature, 343, 636-638, 1990.

Belyayevsky, N.A., The Earth's Crust Within the Territory of the USSR (in Russian), 280 pp., Nedra, Moscow, 1974.

Benedetti, L., Bilan mécanique d'une orogénèse active: Le Tien Shan, rapport de stage effectué dans le laboratoire de tectonique et mécanique de la lithosphère, 23 pp., Institut de Physique du Globe de Paris, 1993.

Berdichevsky, M.N., V.I. Dmitriyev, and I.S. Barashkov, Megnetotelluric sounding of conductivity zones in crust and upper mantle, Izv. Earth Phys., 7, 55-68, 1982.

Bird, P., Lateral extension of lower crust from under high topography in the isostatic limit, J. Geophys. Res., 96, 10275-10286, 1991.

Bott, M.H.P., Evolution of young continental margins, Tectonophysics, 11, 319-327, 1971.

Brace, W.F., and D.L. Kohlstedt, Limits on lithospheric stress imposed by laboratory experiments, J. Geophys. Res., 85, 6248-6252, 1980.

Burov, E.B., and M. Diament, Flexure of the continental lithosphere with multilayered rheology, Geophys. J. Int., 109, 449-468, 1992.

Burov, E.B., M.G. Kogan, H. Lyon-Caen, and P. Molnar, Gravity anomalies, the deep structure, and dynamic processes beneath the Tien Shan, Earth Planet. Sci. Lett., 96, 367-383, 1990.

Burov, E.B., L.I. Lobkovsky, S. Cloetingh, and A.M. Nikishin, Continental lithosphere folding in Central Asia (part 2), Constraints from gravity and topography, Tectonophysics, 226, 73-87, 1993.

Burov, E.B., F. Houdry, M. Diament, and J. Déverchère, A broken plate beneath the North Baikal rift zone revealed by gravity modeling, Geophys. Res. Lett., 21, 129-132, 1994.

Byerlee, J. D., Friction of rocks, Pure Appl. Geophys., 116, 615-626, 1978.

Caldwell, J.G., and D.L. Turcotte, Dependence of the thickness of the elastic lithosphere on age, J. Geophys. Res., 84, 7572-7576, 1979.

Calmant, S., and A. Cazenave, The effective elastic lithosphere under the Cook-Austral and Society islands, Earth Planet Sci. Lett., 77, 187-202, 1986.

Carter, N.L., and M.C. Tsenn, Flow properties of continental lithosphere, Tectonophysics, 36, 27-63, 1987.

Chen, W.P., and P. Molnar, Focal depths of intracontinental earthquakes and their implications for the thermal and mechanical properties of the lithosphere, J. Geophys. Res., 88, 4183-4214, 1983.

Chéry, J., J.P. Vilotte, and M. Daignieres, Thermomechanical evolution of a thinned continental lithosphere under compression: Implications for Pyrenees, J. Geophys. Res., 96, 4385-4412, 1991

Chéry, J., F. Lucozeau, M. Daignieres, and Vilotte, J. P., Large uplift of rift flanks: A genetic link with lithospheric rigidity ?, Earth Planet. Sci. Lett., 112, 195-211, 1992. 
Cloetingh, S., and E. Banda, Europe's lithosphere - physical properties. Mechanical structure, pp. 80-91, edited by D. Blundell, $R$. Freeman, and S. Mueller, A Continent Revealed: the European Geotraverse, Cambridge University Press/European Science Foundation, New York, 1992.

Cloetingh, S.A.P.L., M.J.R. Wortel, and N.J. Vlaar, Evolution of passive continental margins and initiation of subduction zones, Nature, 297, 139-142, 1982.

Cochran, J.R., Some remarks on isostasy and the long-term behaviour of the continental lithosphere, Earth Planet. Sci. Lett., 46, 266-274, 1980.

Deplus, C., Comportement mécanique de la lithosphère océanique: Cas d'une subduction complexe, 402 pp., Ph. d. thesis, Univ. de ParisSud, Centre d' Orsay, 1987.

De Rito, R.F., F.A. Cozzarelli, and D.S. Hodge, A forward approach to the problem of nonlinear viscoelasticity and the thickness of the mechanical lithosphere. J. Geophys. Res., 91, 8295-8313, 1986.

Déverchère, J., F. Houdry, N.V. Solonenko, A.V. Solonenko, and V.A Sankov, Seismicity, active faults and stress field of the North Muya Region, Baikal Rift: New insights on the rheology of extended continental lithosphere, J. Geophys. Res., 98, 19895-19912, 1993.

Dubois, J., J. Launay, and J. Récy, Uplift movements in New Caledonia - Loyalty Islands area and their plate tectonics interpretation, Tectonophysics, 24, 133-150, 1974.

Ebinger, C.J., T.D. Bechtel, Forsyth, D.W. and C.O. Bowin, Effective elastic plate thickness beneath the East African and Afar Plateaux and dynamic compensation of the uplifts, J. Geophys. Res., 94, 2883-2901, 1989.

England, P.C., and S.W. Richardson, Erosion and the age dependence of continental heat flow, Geophys. J. R. Astron. Soc., 62, 421-437, 1980.

Filmer, P.E., M.K. McNutt, and C.J. Wolfe, Elastic thickness of the lithosphere in the Marquesas and Society Islands, J. Geophys. Res., 98, 19565-19577, 1993.

Forsyth, D.W., Comparison of mechanical models of the oceanic lithosphere, J. Geophys. Res., 85, 6364-6368, 1980.

Goetze, C., The mechanisms of creep in olivine, Philos. Trans. $R$. Soc. London A, 288, 99-119, 1978.

Goetze, C., and B. Evans, Stress and temperature in the bending lithosphere as constrained by experimental rock mechanics. Geophys. $J$. R. Astron. Soc., 59, 463-478, 1979.

Govers, R., M.J.R. Wortel, S.A.P.L. Cloetingh, and C.A. Stein, Stress magnitude estimates from earthquakes in oceanic plate interiors, $J$. Geophys. Res., 97, 11749-11759, 1992.

Hopper, J.R., and W.R. Buck, The initiation of rifting at constant tectonic force: Role of diffusion creep, J. Geophys. Res., 98, 16213$16221,1993$.

Jaupart, C., Horizontal heat transfer due to radioactivity contrasts: Causes and consequences of linear heat flow relation, Geophys. $J$. R. Astron. Soc., 75, 411-435, 1983.

Judge, A.V. and M.K. McNutt, The relationship between plate curvature and elastic plate thickness: A study of the Peru-Chile Trench, J. Geophys. Res., 96, 16625-16639, 1991.

Karner, G.D., and A.B. Watts, Gravity anomalies and flexure of the lithosphere at mountain ranges, $J$. Geophys. Res., 88, 10449 $10477,1983$.

Karner, G.D., M.S. Steckler, and J.A. Thorne, Long-term thermomechanical properties of the continental lithosphere, Nature, 304, 250$253,1983$.

Kirby, S.H., Rheology of the lithosphere, Rev. Geophys., 21, 14581487, 1983.

Kirby, S.H., and A.K. Kronenberg, Rheology of the lithosphere: Selected topics, Rev. Geophys., 25, 1219-1244, 1987.

Kruse, S., M. McNutt, J. Phipps-Morgan, and L. Royden, Lithospheric extension near Lake Nevada: A model for ductile flow in the lower crust, J. Geophys. Res., 96, 4435-4456, 1991.

Kruse, S., and L. Royden, Bending and unbending of an elastic lithosphere: The Cenozoic history of the Apennine and Dinaride fordeep basins, Tectonics, 13, 278-302, 1994.

Kusznir, N.J., The distribution of stress with depth in the lithosphere: Thermo-rheological and geodynamic constraints, Philos. Trans. $R$. Soc. London A, 337, 95-110, 1991.
Kusznir, N.J., and G. Karner, Dependence of the flexural rigidity of the continental lithosphere on rheology and temperature, Nature, 316, 138-142, 1985.

Kusznir, N.J., and D.H. Matthews, Deep seismic reflections and the deformational mechanics of the continental lithosphere, $J$. Petrol., 63-87, 1988.

Kusznir, N.J., and R.G. Park, The extensional strength of the continental lithosphere: Its dependence on geothermal gradient, and crustal composition and thickness, in Continental Extensional Tectonics, edited by M.P. Coward, J.F. Dewey, and P.L. Hancock, Geol. Soc. Spec. Publ. London, 28, 35-52, 1987.

Landau, L.D., and E.M. Lifchitz, The Theory of Elasticity (in Russian), 246 pp., Nauka, Moscow, 1987.

Lobkovsky, L.I., Geodynamics of Spreading and Subduction Zones, and the Two-Level Plate Tectonics (in Russian), 251 pp., Nauka, Moscow, 1988.

Lobkovsky, L.I., and V.I. Kerchman, A two-level concept of plate tectonics: Application to geodynamics, Tectonophysics, 199, 343374, 1992.

Long, L.T., and K.H. Zelt, A local weakening of the brittle-ductile transition can explain some intraplate seismic zones, Tectonophysics, 186, 175-192, 1991.

Lyon-Caen, H., and P. Molnar, Constraints on the structure of the Himalaya from an analysis of gravity anomalies and a flexural model of the lithosphere, J. Geophys. Res., 88, 8171-8191, 1983.

Lyon-Caen, H., and P. Molnar, Gravity anomalies and the structure of the western Tibet and the southern Tarim basin, Geophys. Res. Lett., II, 1251-1254, 1984.

Lyon-Caen, H., P. Molnar, and G. Suarez, Gravity anomalies and flexure of the Brazilian shield beneath the Bolivian Andes, Earth Planet. Sci. Lett., 75, 81-92, 1985.

Mackwell, S.J., Q. Bai, and D.L. Kohlstedt, Rheology of olivine and the strength of the lithosphere, Geophys. Res. Lett., 17, 9-12, 1990.

Mareschal, J.C., and A.F. Gangi, Equilibrium position of a phase boundary under horizontally varying surface loads, Geophys. J. R. Astron. Soc., 49, 757-779, 1977.

Mareschal, J.C., and J. Kuang, Intraplate stresses and seismicity: The role of topography and density heterogeneities, Tectonophysics, 132, 153-162, 1986.

McAdoo, D.C., C.F. Martin, and S. Polouse, Seasat observations of flexure: Evidence for a strong lithosphere, Tectonophysics, 116, 209-222, 1985.

McKenzie, D. P., and C. Bowin, The relationship between the bathymetry and gravity in the Atlantic Ocean, J. Geophys. Res., 81, 1903-1915, 1976.

McNutt, M., Implications of regional gravity for state of stress in the Earth's crust and upper mantle, J. Geophys. Res., 85, 6377-6396, 1980.

McNutt, M., Flexure reveals great depth, Nature, 343, 596-597, 1990.

McNutt, M., and H.W. Menard, Constraints on the yield strength in the oceanic lithosphere derived from observations of flexure, Geophys. J. R. Astron. Soc., 59, 4663-4678, 1982.

McNutt, M., M. Diament, and M.G. Kogan, Variations of elastic plate thickness at continental thrust belts, J. Geophys. Res., 93, 88258838, 1988.

Meissner, R., and P. Tapponnier, Limits of stresses in continental crusts and their relation to the depth-frequency distribution of shallow earthquakes, Tectonics, 1, 73-89, 1982.

Melosh, H.J., and C.A. Williams, Jr., Mechanics of graben formation in crustal rocks: A finite element analysis, J. Geophys. Res., 94, 13961-13973, 1989.

Molnar, P., and D. Qidong, Faulting associated with large earthquakes and the average rate of deformation in central and eastern Asia, $J$. Geophys. Res., 89, 6203-6227, 1984.

Molnar P., and Tapponnier, A possible dependence of the tectonic strength on the age of the crust in Asia, Earth Planet. Sci. Lett., 52, 107-114, 1981.

Mômer, N.-A., Glacial isostasy and long-term crustal movements in Fennoscandia with respect to lithospheric and asthenospheric processes and properties, Tectonophysics, 176, 13-24, 1990.

Na, T.Y., Computational Methods in Engineering Boundary value problems, 309 pp., Academic, San Diego, Calif., 1979. 
Okaya, N., S. Cloetingh, F. Freeman, and St. Mueller, A lithospheric cross section along the European geotraverse through the Swiss Alps: An example of continent-continent collision, 2: Aspects of the present-day mechanical structure, Geophys. J. Int., in press, 1994.

Parsons, B., and J.G. Sclater, An analysis of the thermal structure of the plates, J. Geophys. Res., 82, 803-827, 1977.

Ranalli, G., Nonlinear flexure and equivalent mechanical thickness of the lithosphere, Tectonophysics, 240, 107-114, 1994.

Ranalli, G., and D.C. Murphy, Rheological stratification of the lithosphere, Tectonophysics, 132, 281-295, 1987.

Royden, L.H., The tectonic expression slab pull at continental convergent boundaries, Tectonics, 12, 303-325, 1993.

Ruttler, E.H., and K.H. Brodie, The role of tectonic grain size reduction in the rheological stratification of the lithosphere, Geol. Rundsch., 77, 295-308, 1988.

Sahagian, D.L., and S.M. Holland, On the thermo-mechanical evolution of continental lithosphere, $J$. Geophys. Res., 98, 8261$8274,1993$.

Sclater, J.G., C. Jaupart, and D. Galson, The heat flow through oceanic and continental crust and the heat loss of the Earth, Rev. Geophys., 18, 269-311, 1980.

Sheffels, B., and M. McNutt, Role of subsurface loads and regional compensation in the isostatic balance of the Transverse Ranges, California: Evidence of intracontinental subduction, $J$. Geophys. Res., 91, 6419-6431, 1986.

Smith, W.H.F., H. Staudigel, A.B. Watts, and M.S. Pringle, The Magellan Seamounts: Early Cretaceous record of the South Pacific isotopic and thermal anomaly, J. Geophys. Res., 94, 10501-10523, 1989.

Stakhovskaya, R.Y., and M.G. Kogan, Gravity and mechanical modeling of the lithosphere plate's interaction: The regions of Urals and Caucasus (abstract), Terra Nova, 5, suppl. 1, 269, 1993.

Stephenson, R.A., and S. Cloetingh, Some examples and mechanical aspects of continental lithospheric folding, Tectonophysics, 188, 27-37, 1991.

Talwani, P., and K. Rajendran, Some seismological and geometric features of intraplate earthquakes, Tectonophysics, 186, 19-41, 1991.

Timoshenko, S.P., and S. Woinowsky-Krieger, Theory of Plates and Shells, 580 pp., McGraw-Hill, New York, 1959.

Tsenn, M.C., and N.L. Carter, Flow properties of continental lithosphere, Tectonophysics, 136, 27-63, 1987.

Turcotte, D.L., and G. Schubert, Geodynamics. Applications of Continuum Physics to Geological Problems, 450 pp., John Wiley, New York, 1982.
Van der Beek, P.A., and S. Cloetingh, Lithospheric flexure and the tectonic evolution of the Betic Cordilleras (SE Spain), Tectonophysics, 203, 325-344, 1992.

Watts, A.B., An analysis of isostasy in the world's oceans, 1, Hawaiian-Emperor Seamount Chain, J. Geophys. Res., 83, 59896004, 1978.

Watts, A.B., Gravity anomalies, crustal structure and flexure of the lithosphere at the Baltimore Canyon Trough, Earth Planet. Sci. Lett., 89, 221-238, 1988.

Watts, A.B., The effective elastic thickness of the lithosphere and the evolution of foreland basins, Basin Res., 4, 169-178, 1992.

Watts, A.B., and M. Talwani, Gravity anomalies seaward of deep-sea trenches and their tectonic implications, Geophys. J. R. Astron. Soc., 36, 57-90, 1974.

Watts, A.B., and M. Torne, Crustal structure and the mechanical properties of extended continental lithosphere in the Valencia through (western Mediterranean), J. Geol. Soc. London, 149, 813827, 1992.

Watts, A.B., J.H. Bodine, and N.M. Ribe, Observations of flexure and geological evolution of the Pacific Ocean basin, Nature, 283, 532$537,1980$.

Wessel, P., A re-examination of the flexural deformation beneath the Hawaiian islands, J. Geophys. Res., 98, 12177-12190, 1993.

Wessel, P., and W.F. Haxby, Thermal stresses, differential subsidence, and flexure at oceanic fracture zones, $J$. Geophys. Res., 95, 375$391,1990$.

Wever, T., The Conrad discontinuity and the top of the reflective lower crust - Do they coincide?, Tectonophysics, 157, 39-58, 1989.

White, N., and D.P. McKenzie, Formation of the "Steer's Head" geometry of sedimentary basins by differential stretching of the crust and mantle, Geology, 16, 250-253, 1988.

Zoback, M.D., W.H. Prescott, and S.W. Krueger, Evidence for lower crustal strain localisation in elastic thickness of continental thrust belts, Nature, 317, 7705-7707, 1985.

Zoetemeijer, R., P. Desegaulx, S. Cloetingh, F. Roure, and I. Moretti, Lithospheric dynamics and tectonic-stratigraphic evolution of the Ebro Basin, J. Geophys. Res., 95, 2701-2711, 1990.

E. B. Burov and M. Diament, Laboratoire de Gravimétrie et Géodynamique (J.E. 335), Institut de Physique du Globe de Paris, 4 Place Jussieu, 75252, Paris Cedex 05, France. (e-mail: burov@ipgp.jussieu.fr, diament@ipgp.jussieu.fr)

(Received March 10, 1994; revised October 12, 1994; accepted October 19, 1994.) 